\title{
COMPORTAMENTO OLFATIVO DE TRÊS ESPÉCIES DE PARASITÓIDES (HYMENOPTERA: BRACONIDAE) DE MOSCAS-D AS-FRUTAS (DIPTERA: TEPHRITIDAE)
}

José Wilson Pereira da Silva

\begin{abstract}
Dissertação apresentada à Escola Superior de Agricultura "Luiz de Queiroz", Universidade de São Paulo, para obtenção do título de Mestre em Ciências, Área de Concentração: Entomologia.
\end{abstract}

\author{
PIRACICABA \\ Estado de São Paulo - Brasil \\ Junho - 2005
}




\title{
COMPORTAMENTO OLFATIVO DE TRÊS ESPÉCIES DE PARASITÓIDES (HYMENOPTERA: BRACONIDAE) DE MOSCAS-D AS-FRUTAS (DIPTERA: TEPHRITIDAE)
}

\author{
José Wilson Pereira da Silva
}

Engenheiro Agrônomo

Orientador: Prof. Dr. JOSÉ M A URÍCIO SIM ÕES BENTO

\footnotetext{
Dissertação apresentada à Escol a Superior de Agricultura "Luiz de Queiroz", Universidade de São Paulo, para obtenção do título de Mestre em Ciências, Área de Concentração: Entomologia.
}

\author{
PIRACICABA \\ Estado de São Paulo - Brasil \\ Junho - 2005
}


Dados Internacionais de Catalogação na Publicação (CIP) DIVISÃO DE BIBLIOTECA E DOCUMENTAÇÃO - ESALQ/USP

Silva, José Wilson Pereira da

Comportamento olfativo de três espécies de parasitóides (Hymenoptera:

Braconidae) de moscas-das-frutas (Diptera: Tephritidae) / José Wilson Pereira da Silva. - - Piracicaba, 2005.

59 p. : il.

Dissertação (mestrado) - - Escola Superior de Agricultura Luiz de Queiroz, 2005. Bibliografia.

1. Comportamento animal 2. Controle biológico 3. Díptero 4. Himenoptero 5. Inseto-parasitóide 6. Moscas-das-frutas I. Título

CDD 632.774

"Permitida a cópia total ou parcial deste documento, desde que citada a fonte - O autor" 
D etudo ficaram três coisas:

A certeza de que estamos sempre começando....

A certez a de que precisamos continuar.....

A certeza de que seremos interrompidos antes de terminar....

Portanto devemos:

F azer da interrupção, um caminho novo...

$D$ a queda, um passo de dança....

D o medo, uma escada...

Do sonho, uma ponte...

$D$ a procura, um encontro....

(F ernando Pessoa) 
A os meus pais P edro e $R$ osa, pelo esforço que fizeram para que eu chegasse até aqui;

\title{
D edico
}

\author{
A meu irmão I oão e sua esposa $E$ va; \\ A minhas irmãs L ourdes, R osely e R osilene; \\ A os meus sobrinhos A llannah, E laine, J oão P edro, \\ $L$ ucas, $M$ atheus e $P$ edro $H$ enrique
}

\section{Ofereço}




\section{AGRADECIMENTOS}

A o nosso D eus por tudo que tem me permitido al cançar,

Ao Prof. Dr. José Maurício Simões Bento por sua orientação, assim como por seus constantes incentivos, sugestões e não menos importante, pela amizade e crédito dispensados que foram fundamentais neste trabalho,

Ao Prof. Dr. Roberto Antonio Zucchi, pela oportunidade inicial de orientação e possibilidade de ingresso concedida ao curso de pós-graduação em entomologia nesta casa tão conceituada,

À Escola Superior de Agricultura "Luiz de Queiroz" - ESALQ/ USP, por sua magnificência em ensino superior. Sinto-me honrado em ter feito parte desta instituição de ensino,

Ao CNPq - Conselho Nacional de Desenvolvimento Cientifico e Tecnológico pela concessão da bolsa de mestrado ( Proc. № 130725/ 2003-0),

Ao Prof. Dr. José Roberto P. Parra (ESALQ/ USP), pela utilização das dependências e equipamentos do Laboratório de Biologia de Insetos,

A os amigos do Laboratório de Biologia de Insetos, e em especial a Neide que sempre se mostrou atenciosa ep restativa,

A o Prof. Dr. Júlio Walder do Laboratório de Radioentomologia (CENA/ USP), por sua atenção, amizade e fornecimento das larvas de moscas-das-frutas e parasitóides utilizados nos experimentos, 
Aos técnicos do laboratório de radioentomologia Lia, Cristina, Adilson e Luís (CENA -USP) pelo material utilizado, e especialmente, por sua amizade,

A Profạ. Drạ Marinéia de Lara Haddad pelo auxílio nas análises estatísticas,

Ao Prof. Dr. Sinval Silveira Neto pelo auxílio na discussão dos dados e interpretação das análises estatísticas,

Ao Dr. Alberto Arab pelo auxilio na interpretação dos dados e tradução do abrstract,

A Profạ. Drạ Angélica Maria Penteado Dias (UFSCar) pela confirmação da identificação do parasitóideA sobara anastrephae,

Aos professores do Departamento de Entomologia Fitopatologia e Zoologia Agrícola, da ESALQ, pelos conhecimentos transmitidos,

A todos do curso de pós-graduação em Entomologia, em especial aos amigos Bruno, Cristiane Nardi, Fabiana, Edmilson, Élio, Erich, Geraldo, João, Márcio e Wyratan entre outros, amizade de vocês fez diferença,

Aos amigos: Clarette, Cleomilson, Gean Carlos, Jair (Teórico), Salim, Gustavo, Gilson Filho, Prof. J. Marcílio (EAFA), Simão, Salomão, Sula, Luana Carvalho, Milla Ramos, Milena, Miriam, Tauari, Tairon, Tony Marcio, Té e Vivi Araújo, entre tantos outros impossíveis de citar. É gratificante os ter como amigos,

Ao graduando Fernando Colombo de Amo estagiário do laboratório de taxonomia de insetos da (ESALQ-USP) pelo auxilio na identificação das moscas-das-frutas,

Aos professores de Entomologia da UFRuralRJ, Dra Mariângela Guajará, Dr. Francisco Racca e Dr. Eurípides Menezes, responsáveis por meus primeiros passos nesta ciência que a cada dia me apaixona mais. 


\section{SUMÁRIO}

Página

RESUMO

SUMMARY ........................................................................................

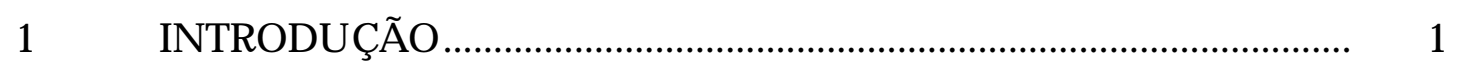

2 REVISÃO DE LITERATURA

2.1 Aspectos gerais............................................................................. 3

2.2 Moscas-das-frutas no Brasil ................................................................ 3

2.3 Himenópteros parasitóides............................................................... 4

2.3.1 Diachasmimorpha longicaudata............................................................ 5

2.3.2 Parasitóides nativos............................................................................ 6

2.4 Controle biológico de moscas-das-frutas............................................. 8

2.5 Comportamento................................................................................ 9

2.6 Aprendizagem de parasitóides........................................................ 10

2.7 Busca e localização.......................................................................... 11

2.8 Localização do hospedeiro a curta distância....................................... 13

3 MATERIAL E MÉTODOS .......................................................... 14

3.1 Obtenção e manutenção de parasitóides............................................. 14

3.1.1 Parasitóide exótico, D iachasmimorpha longicaudata A shmead ................ 14

3.1.2 Parasitóides nativos, Doryctobracon areolatus (Szépligeti) e A sobara anastrephae (Muesebeck) .............................................................. 15

3.2 Obtenção e manutenção de moscas-das-frutas.................................... 17 
3.2.1 Ceratitis capitata................................................................................ 17

3.2.2 A nastrepha fraterculus .................................................................. 18

3.3 Resposta dos parasitóides aos voláteis................................................. 20

3.4 Avaliação em telado .......................................................................... 25

3.5 Análises Estatísticas ............................................................................. 26

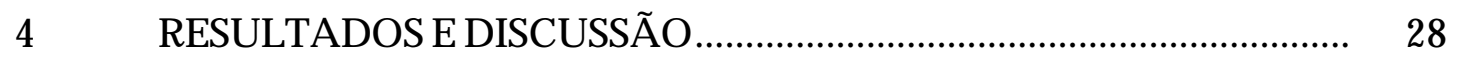

$4.1 \quad$ Resposta ol fativa.................................................................... 28

4.1.1 Resposta ol fativa de D. Iongicaudata aos voláteis de goiaba podre....... 28

4.1.2 Resposta olfativa de D. Iongicaudata e D. areolatus a voláteis de goiaba em maturação inicial (devez) e podre.................................... 29

4.1.3 Resposta olfativa de D. Iongicaudata e D. areolatus a voláteis de goiabas podres com e sem larvas de moscas-das-frutas

4.1.4 Resposta olfativa de D. Iongicaudata a voláteis de goiaba com larvas de $C$ eratitis capitata em diferentes idades

4.1.5 Resposta olfativa de D. longicaudata, $D$. areolatus e A. anastrephae a voláteis de goiaba com larvas de $C$. capitata e A. fraterculus.

4.1.6 Controle branco $x$ branco .................................................................... 39

4.1.7 Comportamento olfativo de D. Iongicaudata e D. areolatus em telado

4.2 Considerações finais........................................................................ 43

5 CONCLUSÕES............................................................................ 44

REFERÊN CIAS BIBLIOGRÁFICAS............................................................. 46 


\title{
COMPORTAMENTO OLFATIVO DE TRÊS ESPÉCIES DE PARASITÓIDES (HYMEN OPTERA: BRACONIDAE) DE MOSCAS-DAS-FRUTAS (DIPTERA: TEPHRITIDAE )
}

\author{
Autor: JOSÉ WILSON PEREIRA DA SILVA \\ Orientador: Prof. Dr. JOSÉ MAURÍCIO SIMÕES BENTO
}

\section{RESUMO}

Entre os inimigos naturais das moscas-das-frutas, os representantes da subfamília Opiinae (Hymenoptera: Braconidae) têm sido os mais utilizados em programas de controle biológico. Entretanto, algumas espécies da subfamília Alysiinae são comumente relacionadas ao parasitismo desses dípteros, em particular Asobara anastrephae (Muesebeck). No estudo da eficiência desses parasitóides é de fundamental importância o conhecimento dos estímulos utilizados para a local ização do hábitat de seus hospedeiros. Dessa forma, foram avaliadas as respostas olfativas do parasitóide exótico Diachasmimorpha longicaudata Ashmead, e dos nativos, Doryctobracon areolatus (Szépligeti) e A. anastrephae a frutos de goiaba (Psidium guajava L.) com e sem larvas de moscasdas-frutas, em condições de laboratório. D. Iongicaudata e D. areolatus foram também estudados em telado. As fêmeas de D. longicaudata e de D. areolatus 
responderam aos odores de frutos podres não-infestados, embora D. areolatus também tenha sido atraído aos frutos em maturação inicial (de vez). As fêmeas dessas espécies demonstraram reconhecer os voláteis de frutos com larvas de Ceratitis capitata (Wied.). No entanto, em bioensaios realizados com frutos contendo larvas de diferentes instares, as fêmeas de D. Iongicaudata não foram capazes de separar frutos com larvas dos primeiros instares dos de terceiro instar de C. capitata. Nas avaliações dos voláteis liberados dos frutos com larvas de C. capitata e de A nastrepha fraterculus (Wied.), as fêmeas de D. Iongicaudata orientaram-se aos voláteis dos frutos com ambas as espécies de hospedeiros, mas diferiram significativamente dos voláteis com larvas de C. capitata. As fêmeas de $D$. areolatus também demonstraram respostas para ambas as espécies, mas diferiram significativamente dos voláteis de frutos com larvas de A. fraterculus. As fêmeas de A . anastrephae orientaram-se de forma similar para os campos com odores de frutos infestados com ambas as espécies de moscas-dasfrutas. Em área coberta (telado), as fêmeas de D. Iongicaudata orientaram-se pelos voláteis de frutos podres com e sem larvas, porém não diferenciaram significativamente os hospedeiros. As fêmeas de $D$. areolatus não foram atraídas para os frutos nas gaiolas no solo independentemente do hospedeiro, sugerindo que este parasitóide não forrageia em frutos caídos. 


\title{
OLFACTORY BEHAVIOR OF THREE PARASITOID SPECIES (HYMENOPTERA: BRACONIDAE) OF FRUIT FLIES (DIPTERA: TEPH RITIDAE )
}

\author{
Author: JOSÉ WILSON PEREIRA DA SILVA \\ Adviser: Prof. Dr. JOSÉ MAURÍCIO SIMÕES BENTO
}

\section{SUM MARY}

Parasitoids of the Opiinae subfamily (Hymenoptera: Braconidae) are among the most used natural enemies in fruit fly control programs. Furthermore, some species of the subfamily Alysiinae, such as A sobara anastrephae (Muesebeck), are commonly associated to the parasitism of these dipterans. The study of efficiency of parasitoids is essential in order to understand the mechanisms that regulate both prey and habitat searching behavior of natural enemies. In this work we evaluated the behavioral response of the native parasitoid species Doryctobracon areolatus (Szépligeti), A. anastrephae as well as the exotic species Diachasmimorpha longicaudata Ashmead, to guava fruit (Psidium guajava L.) with and without fruit flies larvae under laboratory conditions. In addition, behavioral response of D. Iongicaudata and D. areolatus were also determined under natural conditions. Parasitoid females of 
D. Iongicaudata and D. areolatus responded to volatiles from non-infested fermented fruits, moreover $D$. areolatus also attracted to fruits on initial maturation. Both species recognized volatiles from fruits infested with Ceratitis capitata (Wied.) larvae; however D. Iongicaudata females were unable to differentiate volatiles from fruit infested with different larval instars of $\mathrm{C}$. capitata. Olfactometer choice bioassays showed that females of both parasitoid species oriented to volatiles released from fruits infested with C. capitata and A nastrepha fraterculus (Wied.) larvae, however preference differed significantly for volatiles associated with each fruit fly species. Under natural conditions, D. longicaudata was attracted to volatiles released from infested and non-infested fermented fruits. Nevertheless, D. areolatus did not respond to volatiles from infested fruits placed on the ground, suggesting that this species do not prey on fallen fruits. 


\section{INTRODUÇÃO}

O uso de parasitóides para o controle biológico de moscas-das-frutas (Diptera: Tephritidae) teve início no prinćpio do século XX na Austrália (Wharton, 1989) e Europa (Liedo \& Cancino, 2000). A partir daí, diversos programas de controle biológico de tefritídeos foram conduzidos em todo mundo (Clausen, 1956; Wharton, 1989; Gingrich, 1993). No Brasil, recentemente, um programa de controle biológico foi iniciado com a introdução de Diachasmimorpha longicaudata (A shmead) (Walder et al., 1995; Carvalho et al., 2000).

As moscas-das-frutas são consideradas as principais pragas da fruticultura mundial, pois suas larvas se alimentam dos frutos tornando-os impróprios para a indústria e o consumo in natura. As medidas de controle disponíveis, incluindo as químicas, físicas e biológicas, visam reduzir e/ ou erradicar as populações de moscas-das-frutas. Entre estas medidas, o controle biológico tem se destacado como promissor em diversos países (Clausen, 1956; Wharton, 1989; Liedo \& Cancino, 2000; Cancino, 2002). Entretanto, o sucesso de muitos programas de controle biológico depende de estudos básicos sobre o inimigo natural, incluindo taxonomia, biologia, comportamento, distribuição geográfica e interações com o ambiente (Wharton, 1989; Leonel Jr et al., 1995). 
No Brasil, principalmente os estudos taxonômicos, de distribuição geográfica e relação tritrófica, avançaram nos últimos 15 anos (Canal \& Zucchi, 2000). Contudo, pouco ainda se sabe sobre o comportamento olfativo do braconídeo exótico D. Iongicaudata) nas condições brasileiras assim como dos braconídeos nativos.

Assim, o presente trabalho teve os seguintes objetivos: (i) estudar a resposta olfativa do parasitóide exótico $D$. Iongicaudata e dos nativos Doryctobracon areolatus (Szépligeti) e Asobara anastrephae (Muesebeck) (Hymenoptera: Braconidae) aos voláteis de frutos de goiaba (Psidium guajava L.), em diferentes estágios de maturação, com e sem larvas de Ceratitis capitata (Wied.) e A nastrepha fraterculus (Wied.), e (ii) verificar as respostas olfativas de D. longicaudata e $\mathrm{D}$. areolatus a goiabas com e sem larvas destes dois hospedeiros, em condições de área coberta (telado). 


\section{REVISÃO DE LITERATURA}

\subsection{A spectos gerais}

A produção mundial de frutas é de aproximadamente 540 milhões de toneladas, na qual o Brasil contribui com cerca de $8 \%$, destacando-se como o terceiro produtor atrás apenas da China e Índia. Contudo, apesar do grande potencial, a participação brasileira no mercado internacional ainda é inexpressiva, com poucas exceções (Andrigueto \& Kososki, 2003). Entre as dificuldades enfrentadas pelo Brasil, destacam-se às barreiras comerciais e fitossanitárias, especialmente estas, que restringem a exportação de frutas frescas devido ao ataque das moscas-das-frutas (Carval ho et al., 2000; Araújo, 2002; Carvalho, 2003).

\subsection{M oscas-das-frutas no Brasil}

As moscas-das-frutas presentes no Brasil pertencem aos gêneros A nastrepha, Ceratitis, Rhagoletis e Bactrocera, destacando-se os dois primeiros por sua ampla distribuição e número de hospedeiros. As espécies de R hagoletis estão restritas ao sul do país e a mosca-da-carambola, Bactrocera carambolae Drew \& Hancock, única espécie deste gênero assinalada no país, encontra-se restrita ao Oiapoque, Amapá. (Zucchi, 2000c). A mosca-do-mediterrâneo, C. capitata, é a praga de maior destaque na fruticultura mundial, sendo considerada a mais polífaga e invasora das espécies de tefritídeos, com enorme capacidade adaptativa a diferentes hospedeiros e regiões (Liedo \& Cancino, 2000; Zucchi, 
2000b). Em razão disso, diversos países impõem barreiras fito ssanitárias para o comércio de frutas in natura, com o intuito de impedir a entrada da mosca-domediterrâneo (Araújo, 2002; Carvalho, 2002; N ascimento \& Carvalho, 2000). No Brasil, C. capitata é a única espécie do gênero, tendo sido registrada no início do século XX (Ihering, 1901). Em todo o mundo, a mosca-do-mediterrâneo ataca 374 espécies de hospedeiros pertencentes a 69 famílias e no Brasil, 58 espécies dos quais 20 são espécies nativas (Zucchi 2000a).

Entre as espécies de A nastrepha, a maioria ocorre na região Neotropical e um pequeno número no sul da região Neártica (Malavasi et al., 2000). No Brasil, além das 94 espécies alistadas por Zucchi (2000c), recentemente A nastrepha pulchra Stone foi constatada no Estado do Amazonas (Ronchi-Teles, 2002), total izando 95 espécies no país.

No Brasil, são conhecidas 31 famílias de plantas hospedeiras de A nastrepha spp., das quais as famílias M yrtaceae e Sapotaceae representam cerca de 37 e 24\%, respectivamente, das espécies de hospedeiros infestados, sendo A nastrepha obliqua (Macq.) e A nastrepha fraterculus (Wied.) as espécies mais polífagas, infestando 28 e 67 espécies de hospedeiros, respectivamente (Zucchi, 2000a).

\subsection{Himenópteros parasitóides}

Os parasitóides de moscas-das-frutas distribuem-se entre as famílias Braconidae, Diapriidae, Figitidae, Eulophidae e Pteromalidae (Ovruski, 2000). Os braconídeos destacam-se por sua especificidade e eficiência (Clausen, 1956; Wharton \& Gilstrap, 1983; Baranowski et al., 1993; Mendes, 2001).

Entre os braconídeos, as subfamílias Opiinae e Alysiinae formam um grupo monofilético de endoparasitóides cenobiontes larval-pupal (oviposita na larva do hospedeiro e emerge no pupário) (Gauld \& Bolton; 1988; Wharton, 
1993; 1997c, 1997b), exceto os opiíneos do gênero Fopius que são endoparasitóides de ovo-pupa e ocasionalmente atacam larvas de primeiro instar (Lopez et al., 2003).

A subfamília Opiinae possui aproximadamente 1.300 espécies, distribuídas principalmente nos gêneros Biosteres Föerster, 1862; D iachasmimorpha Viereck, 1913; D oryctobracon Enderlein, 1920; Fopius Wharton, 1987; O pius Wesmael, 1835; e U tetes Föerster, 1862 (Wharton \& Gilstrap, 1983; Wharton, 1997a; Ovruski et al., 2000). A subfamília Alysiinae possui cerca de 1.000 espécies, das quais somente os gêneros A sobara Föerster, 1862; e M icrocrasis Fischer estão associadas às moscas-das-frutas. Vale ressaltar, que para o gênero A sobara, somente A . anastrephae (Muesebeck) e A . rubra (Papp) são parasitóides de tefritídeos, sendo as demais espécies relacionadas ao parasitismo de larvas de Drosophilidae (Wharton, 1997b; Ovruski, 2000).

Portanto, os opiíneos são o grupo mais abundante de parasitóides de Tephritidae e também os mais amplamente estudados e utilizados em programas de controle biológico de larvas frugívoras (Gauld \& Bolton, 1988; Wharton, 1988; 1993).

\subsubsection{D iachasmimorpha longicaudata}

É um endoparasitóide solitário de larvas de terceiro instar de larvas de moscas-das-frutas (Wharton \& Gilstrap, 1983). É originário da região Indoaustraliana de onde foi trazido e introduzido na década de 40 no Havaí (EUA) para o controle de Bactrocera dorsalis (Hendel) e, em 1950, no México, para o controle deA nastrepha ludens (Loew) (Clausen, 1956; Liedo \& Cancino, 2000). Na década de 60 foi introduzido na Argentina para o controle de C. capitata e A. fraterculus (Schliserman et al., 2003) e na Flórida (EUA) visando o controle de 
A nastrepha suspensa (Loew), onde se estabeleceu rapidamente (Greany et al., 1976), assim como em vários outros países (Ovruski et al., 2000).

No Brasil foi introduzido nos anos 90, pela Embrapa Meio A mbiente em Jaguariúna-SP e Embrapa Mandioca e Fruticultura, em Cruz das AImas-BA, vindo da Flórida (EUA) (Walder et al., 1995; Carvalho et al., 2000). A partir daí, foi enviado para laboratórios especializados de diferentes regiões do país. No Estado de São Paulo, por exemplo, o laboratório de radioentomologia do Centro de Energia Nuclear na Agricultura da Universidade de São Paulo (CENA-USP) em Piracicaba-SP, onde é produzido em escala massal sobre larvas do 3으 instar deC. capitata irradiadas (Walder et al., 1995).

Atualmente é o parasitóide mais estudado e utilizado no controle biológico de moscas-das-frutas em todo o mundo, destacando-se no controle de A nastrepha spp. (Baranowski et al., 1993; Walder et al., 1995; Lopez et al., 1999; Carvalho \& Nascimento, 2000; Cancino, 2002; Carvalho, 2003).

\subsubsection{Parasitóides nativos}

Dos parasitóides nativos coletados em diferentes regiões do Brasil, as espécies que mais se destacam no parasitismo de moscas-das-frutas são: D oryctobracon areolatus (Szépligeti), D oryctobracon brasiliensis (Szépligeti), O pius bellus Gahan, O pius sp. e U tetes anastrephae (Viereck) da subfamília Opiinae e A sobara anastrephae (Muesebeck) da subfamília Alyssinae(Leonel Jr., 1991; Canal et al., 1995; Leonel Jr. et al., 1995; 1996; Canal \& Zucchi, 2000; A raújo \& Zucchi, 2002).

D. areolatus é a espécie neotropical mais abundante e freqüente em diferentes regiões do Brasil, parasitando larvas de A nastrepha spp. em diversas frutíferas, ocorrendo desde o sul dos EUA atéa Argentina (Leonel Jr. et al., 1995; Ovruski et al., 2000). Levantamentos realizados sobre inimigos naturais 
associados a tefritídeos no Brasil e México, enfatizam a abundância e predominância desta espécie em diferentes localidades sobre os demais parasitóides (Leonel Jr. et al., 1995; Matrangolo et al., 1998; Lopez et al., 1999; Canal \& Zucchi, 2000; Aguiar-Menezes et al., 2001; Araújo \& Zucchi, 2002; Uchôa-Fernandes et al., 2003).

Para alguns autores, o predomínio de D. areolatus é devido ao fato de atacar larvas de instares iniciais, parasitando-as ainda na planta e em frutos em estágios iniciais de maturação, e dessa forma, é um dos mais importantes inimigos naturais das moscas-das-frutas (Matrangolo, 1998; Carvalho et al., 2000).

Das espécies de Asobara, relacionadas ao parasitismo de dípteros ciclorrafos, duas espécies - A. anastrephae e A. rubra - parasitam tefritídeos (Wharton, 1994), porém somente a primeira ocorre no Brasil, sendo corriqueiramente relacionada ao parasitismo de A nastrepha spp. (Leonel Jr. et al., 1995; 1996; Canal \& Zucchi, 2000; A raújo \& Zucchi, 2002; Uchôa-Fernandes et al., 2003).

Estudando o parasitismo de moscas-das-frutas em dois municípios do Estado de São Paulo, Leonel Jr. et al. (1996) reportaram a superioridade dos opiíneos, e em particular de D. areolatus, e o associaram cinco espécies de moscas-das-frutas, dentre as quais $A$. fraterculus e $C$. capitata. Além disso, estes autores associaram A . anastrephae ao parasitismo de A nastrepha spp.

Canal et al. (1995), no Estado do Amazonas, associaram o parasitismo de D. areolatus a várias espécies de A nastrepha, assim como A. anastrephae em A. obliqua. Por outro lado, Uchôa-Fernandes et al. (2003), no Estado do Mato Grosso, os braconídeos recuperados estiveram relacionados às espécies de A nastrepha ea C. capitata.

Aguiar-Menezes \& Menezes (2001), estudando a flutuação populacional e o parasitismo de Opiinae no Estado do Rio de Janeiro, determinaram a 
abundância e freqüência de D. areolatus em diferentes épocas do ano, associando-o ao parasitismo de cinco espécies de A nastrepha.

Leonel Jr. et al. (1995), avaliando a distribuição de braconídeos parasitóides de moscas-das-frutas no Brasil, associaram D. areolatus a 10 espécies de moscas-das-frutas em 10 famílias de frutíferas. Os mesmos autores também verificaram o parasitismo de A. anastrephae em A nastrepha sp. e A. obliqua, demonstrando a importância desses inimigos naturais na supressão de tefritídeos.

\subsection{Controle biológico de moscas-das-frutas}

No princípio do século XX, duas expedições quase que simultaneamente iniciaram a busca de inimigos naturais para o controle de moscas-das-frutas. Por volta de 1904, George Compere, introduziu na Austrália o parasitóide A ceratoneuromya indica Silvestri (Hymenoptera: Eulophidae), oriundo da Índia para o controle de C. capitata sem, no entanto, obter êxito (Wharton, 1989; Liedo \& Cancino, 2000; Ovruski et al., 2000). Entre os anos de 1909-1937, Fillipo Silvestri introduziu na Itália, parasitóides para o controle de C. capitata e, em 1910, em outros países da Europa para o controle da mosca-da-oliveira Bactrocera ol eae (Gmelin), não obtendo êxito em ambos os casos (Clausen, 1956). Por outro lado, foi a invasão de C. capitata seguida da constatação da mosca-domelão Bactrocera cucurbitae (Coquillett), na década de 10 e da mosca-oriental Bactrocera dorsalis (Hendel) na década de 40, do século XX, no Havaí (EUA), que fizeram surgir uma maior conscientização no uso do controle biológico de tefritídeos por meio de parasitóides (Clausen, 1956). A partir daí, diversos programas de controle biológico de moscas-das-frutas com parasitóides foram conduzidos em todo o mundo (Clausen, 1956; Wharton, 1989; Gingrich, 1993). 
No Brasil, o controle biológico de moscas-das-frutas teve início somente em meados da década de 90, com a introdução do parasitóide $D$. longicaudata, porém ainda com resultados incipientes (Walder et al., 1995; Carvalho et al., 2000).

O manejo de moscas-das-frutas no Brasil, sempre foi realizado basicamente por meio de produtos químicos (iscas tóxicas e pulverização em cobertura). Todavia, restrições quarentenárias aos resíduos químicos dos inseticidas presente nos frutos, a aquisição de resistência das populações de moscas-das-frutas, desequilíbrios biológicos e a contaminação ambiental têm restringido seu uso (Branco et al., 2000; Carvalho, 2004). Sendo assim, novas estratégias voltadas para o controle biológico têm sido incorporadas ao manejo dessas pragas (Walder et al., 1995; Walder, 2000; M alavasi et al., 2000; Carvalho, 2002).

\subsection{Comportamento}

Ao longo do processo evolutivo, os parasitóides têm explorado os aleloquímicos liberados pelas plantas, como fonte segura de informação para a localização do hábitat e seleção do hospedeiro (Vinson, 1976; Edwards \& Wratten, 1981). Com isso, muitas informações liberadas pelas plantas podem ter influência decisiva no comportamento de seleção do parasitóide, similar às liberadas diretamente pelo inseto hospedeiro (Vet \& Dick, 1992). Contudo, a resposta dos parasitóides a determinados odores que possam indicar o hábitat do hospedeiro, é influenciada por fatores intrínsecos (idade e maturação sexual da fêmea do parasitóide) (Lewis et al. apud Jones, 1986) e por fatores extrínsecos (temperatura, umidade, intensidade de luz, taxa de emissão de moléculas, velocidade e direção do vento, distância entre o parasitóide e a fonte de odor, e 
aos demais odores presentes no ar) (Vinson, 1976; Turlings et al., 1993). Dessa forma, para o sucesso de todo o processo de busca e localização do parasitóide, existe uma hierarquia de estímul os comportamentais e respostas associadas com o hospedeiro e seu hábitat (Vinson, 1976; Eiras \& Gerk, 2001).

Os parasitóides são capazes de detectar uma grande variedade de substâncias químicas potencialmente importantes e determinar sua significância no contexto do ambiente que o circunda. Podem encontrar várias espécies de hospedeiros na mesma localidade, que podem ser adequadas ou não ao parasitismo e, desse modo, a sobrevivência da progênie está diretamente relacionada com a escol ha correta durante esse forrageamento (Tumlinson et al ., 1993). De acordo com Lewis \& Martin (1990), os estímulos visuais e olfativos percebidos pelos parasitóides são duas entradas sensoriais importantes que controlam seu comportamento. Estes estímulos são percebidos por receptores periféricos localizados nas antenas e olhos compostos e o comportamento resultante é expresso por meio do vôo, sondagem e oviposição.

Em razão da complexidade de estímulos do ambiente que o parasitóide deve superar, torna-se evidente a necessidade de um processo de aprendizagem como mecanismo de sucesso no forrageamento.

\subsection{A prendizagem de parasitóides}

Dentro do arranjo estrutural do ambiente que os parasitóides ocupam, encontrar um hospedeiro adequado pode ser uma tarefa complexa. Os parasitóides utilizam mecanismos de orientação aos seus hospedeiros, por meio de sinais químicos, físicos e visuais (Jones, 1986). Dessa forma, o processo de aprendizagem é um elemento essencial na estratégia de forrageamento dos parasitóides e pode ser definida como uma mudança no comportamento devido 
ao resultado de uma experiência prévia bem-sucedida (Turlings et al., 1993; Eiras \& Gerk, 2001).

As respostas aos voláteis relacionados com a localização e reconhecimento do hospedeiro modificam-se com uma experiência bemsucedida, conduzindo a um comportamento voltado às características do hospedeiro (Vinson, 1976). Este é um tipo de mecanismo comum entre os parasitóides, sendo dessa forma denominado de aprendizagem associativa (Lewis \& Tumlinson, 1988; Turlings et al., 1993), onde a habilidade dos parasitóides em aprender permite-Ihes distinguir odores específicos entre voláteis provenientes de diferentes tipos de danos causados às plantas (De Jong \& Kaiser, 1991) ou produzidos por organismos associados (Greany et al., 1977).

\subsection{Busca e localização}

Muitas das discussões sobre o comportamento dos parasitóides focalizam os estímulos visuais e olfativos, importantes na orientação (Greany et al., 1977; Edwards \& Wratten, 1983; Jones, 1986; Messing \& Jang, 1992; Farias \& Hopper, 1997; Siqueira \& Farias, 2003) e os efeitos da experiência, aprendizagem e preferência do hospedeiro (Turlings et al., 1993). O encontro e o reconhecimento do hospedeiro são processos comportamentais distintos, onde ro primeiro, a percepção do encontro do hospedeiro pelo inseto provoca um movimento orientado em direção à fonte, no qual a detecção do estímulo "correto" durante o processo de reconhecimento, que se segue à aterrisagem geralmente reduz esse movimento (Edwards \& Wratten, 1981). As substâncias químicas voláteis liberadas diretamente pelas plantas ou pelas estruturas atacadas como resultado direto ou indireto da atividade de alimentação do hospedeiro, são importantes neste processo (Lewis \& Martin, 1990; Turlings et al., 1993; Paré \& Tumlinson, 1999). As substâncias voláteis atrativas (cairomônios) freqüentemente atraem o 
parasitóide ao hábitat do hospedeiro, enquanto as substâncias menos voláteis podem exercer papel importante na localização a curta distância (Vinson, 1976; Greany et al., 1984).

Diversos estudos têm mostrado que os parasitóides braconídeos de larvas frugívoras orientam-se para o hábitat de seus hospedeiros, guiados por odores liberados por frutos podres (em fermentação). Greany et al. (1977) evidenciaram a importância dos voláteis de pêssegos podres na orientação de D. Iongicaudata, assim como também a atratividade destes parasitóides a voláteis de compostos como acetaldeido, etanol e acido acético. Henneman et al. (2002), estudando o comportamento de localização e parasitismo de larvas de Rhagoletis spp. em frutos de nogueira, verificaram que as fêmeas do parasitóide Diachasmimorpha juglandis (Muesebeck) orientaram-se através dos voláteis liberados dessa associação entre larva e hospedeiro em frutos de nogueira.

A orientação de fêmeas sem experiência de $D$. Iongicaudata a voláteis de citros e manga não-infestadas e infestadas com A. ludens e A nastrepha obliqua (Macquart) é realizada em que haja preferência por esses hospedeiros (Eben et al. 2000). Ainda segundo esses autores, não há respostas às frutas não-infestadas quando comparados com frutas infestadas.

Messing \& Jang (1992), em experimento de orientação de machos e fêmeas do parasitóide $D$. Iongicaudata a diferentes cores de substrato e a odores de frutas, observaram que os machos demonstraram uma resposta visual considerada às esferas coloridas e respostas olfativas baixas, enquanto as fêmeas tiveram melhor resposta para as informações olfativas que visuais. Em experimento semelhante, Henneman (1998) verificou a preferência de $D$. juglandis a frutos amarelos em relação aos escuros e, sugeriu que o contraste visual pode ser a razão da preferência de parasitismo de $D$. juglandis aos frutos amarelos, apesar de ser mais provável a ocorrência de larvas nos frutos escuros do que nos amarelos. Do mesmo modo, pistas visuais também foram 
observadas na atração de D. Iongicaudata e D . juglandis em túnel de vento (Jang et al., 2000).

Eitam et al. (2003), avaliando um método de criação do parasitóide D. areolatus a partir da incorporação de voláteis químicos de pêra nas unidades de oviposição, determinaram que as fêmeas do parasitóide provavelmente se orientaram pelos sinais químicos liberados desses frutos.

\subsection{Localização do hospedeiro a curta distância}

A determinação do possível hábitat do hospedeiro é assegurada por informações químicas e visuais que chegam aos receptores periféricos dos parasitóides. No entanto, as larvas de moscas-das-frutas se encontram no interior dos frutos e dessa forma existe a necessidade de uma estratégia de localização a curta distância. No interior do fruto a larva produz vibrações por sua movimentação e atividade alimentar. Estas vibrações associadas a compostos químicos oriundos de produto de fermentação produzem informações confiáveis para a localização da larva (Lawrence, 1981; Carval ho \& Nascimento 2002). A orientação do parasitóide pela movimentação da larva no interior do fruto é denominada vibrotaxia Lawrence, 1981; Glas \& Vet, 1983; Carvalho, 2003). A vibrotaxia já foi demonstrada em diversas espécies de parasitóides de moscas frugívoras, incluindo Diachasmimorpha mellea (Gahan) por Lathrop \& Newton, (1933), D. Iongicaudata por Lawrence (1981), Diachasma alloeum (M uesebeck) por Glas \& Vet (1983) e para Ganaspis pelleranoi (Brèthes) e 0 dontosema al binerveKieffer por Guimarães (2002). 


\section{MATERIAL E MÉTODOS}

\subsection{0 btenção e manutenção dos parasitóides}

\subsubsection{Parasitóide exótico, Diachasmimorpha Iongicaudata Ashmead}

Fêmeas de D. Iongicaudata foram obtidas a partir de uma đriação massal de Ceratitis capitata (Wied), do Laboratório de Radioentomologia do Centro de Energia Nuclear na A gricultura (CENA-USP), em Piracicaba-SP. As pupas de C. capitata parasitadas por D . longicaudata foram colocadas em gaiolas plásticas de $30 \times 25 \mathrm{~cm}$, com uma abertura central de $20 \mathrm{~cm}$ de diâmetro, revestida de voile (Figura $1 \mathrm{~A}$ ). Essas gaiolas foram mantidas em sala com temperatura de $26 \pm 2^{\circ} \mathrm{C}$, umidade relativa de $60 \pm 10 \%$ e fotofase de 14 horas, no Laboratório de Biologia de Insetos do Departamento de Entomologia, Fitopatologia e Zoologia Agrícola da Escola Superior de Agricultura “Luiz de Queiroz" (ESALQ), Universidade de São Paulo (USP), em Piracicaba-SP. À medida que os adultos de D. Iongicaudata emergiam eram transferidos em outras gaiolas de mesmas dimensões de acordo com sua data de emergência, mantendo-se cerca de 40 casais por gaiola com idade conhecida. Os parasitóides foram alimentados com dieta artificial composta de mel $(0,5 \mathrm{~g})$, água destilada $(500 \mathrm{ml})$, ágar $(10 \mathrm{~g})$, ácido ascórbico $(0,25 \mathrm{~g})$ e benzoato de sódio $(0,05 \mathrm{~g})$, segundo metodologia utilizada pelo CENA-USP (Burns, 1993, Walder et al., 1995) (Figura 1B). 

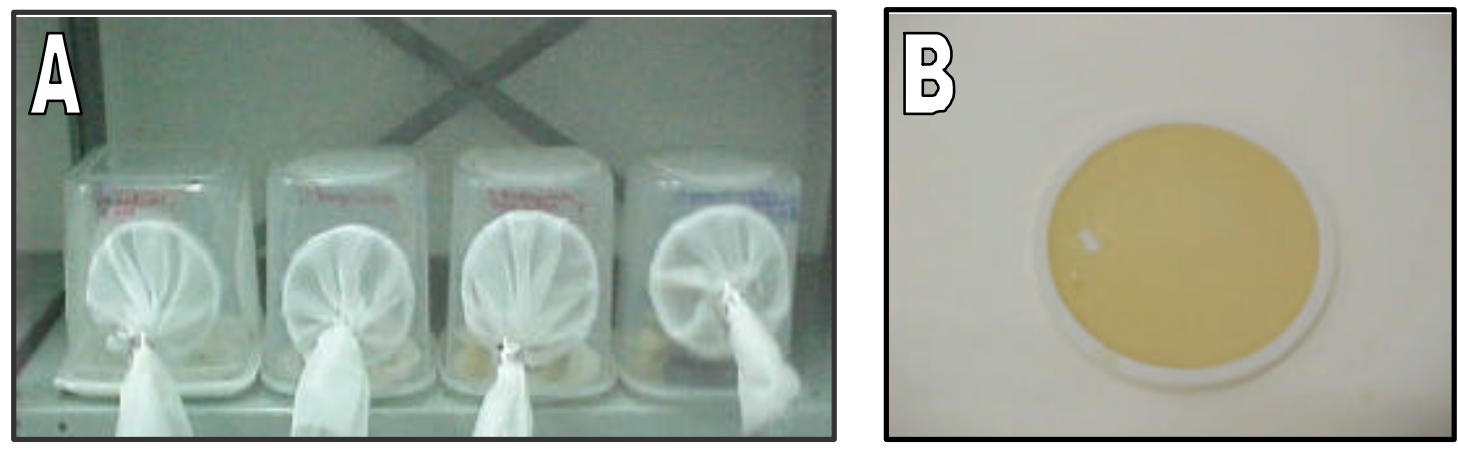

Figura 1 - Sistema de criação do parasitóide exótico Diachasmimorpha longicaudata em laboratório. (A) Gaiolas para manutenção de adultos com idades conhecidas; e (B) Detalhe da dieta utilizada para a alimentação dos adultos

Para as aval iações de D . Iongicau data aos voláteis de frutos, foram testadas somente fêmeas acasaladas e inexperientes, com quatro dias de idade, pois segundo Sugayama (2000), este parasitóide atinge a máxima capacidade de parasitismo no período compreendido entre 4 e 13 dias de idade. Após os biensaios as fêmeas foram fixadas em álcool $70 \%$.

\subsubsection{Parasitóides nativos, Doryctobracon areolatus (Szépligeti) e Asobara anastrephae (M uesebeck)}

Esses parasitóides foram obtidos a partir de coletas esporádicas de aproximadamente 300 frutos de goiaba (Psidium guajava L.) e 1.200 frutos de serigüela (Spondias purpurea L.) no campus da Escola Superior de Agricultura “Luiz de Queiroz" (ESALQ-USP), em PiracicabaSP. As coletas de goiaba ocorreram no período de janeiro a fevereiro de 2005 , e as de serigüela durante o mês de março de 2005, ambas a partir de frutos caídos sob a copa das árvores (Figura 2A, B). 
A pós a coleta, os frutos foram acondicionados em bandejas plásticas de 50 x $70 \mathrm{~cm}$ contendo vermiculita, mantidas em casa-de-vegetação com temperatura de $25 \pm 5^{\circ} \mathrm{C}$, umidade relativa de $60 \pm 10 \%$ e luz natural, no Departamento de Entomologia, Fitopatologia e Zoologia Agrícola da ESALQUSP (Figura 2C). Depois de 10 dias, os frutos de goiaba e serigüela foram retirados das bandejas e a vermiculita peneirada para a obtenção dos pupários, que foram transferidas para gaiolas de acrílico de $50 \times 50 \mathrm{~cm}$ (Figuras 2D, E, eF), até a emergência dos parasitóides, quando eram transferidos separadamente para gaiolas plásticas de $15 \times 25 \mathrm{~cm}$ (Figura 2F), contendo água e dieta similar à fornecida a D . Iongicaudata (item 3.1.1).

A separação preliminar das espécies de parasitóides nativos, D. areolatus e A. anastrephae foram realizadas de acordo com Canal \& Zucchi (2000). A identificação de $A$. anastrephae foi confirmada pela Dra. Angélica Maria Penteado Dias (UFSCar), visto que todos os espécimens avaliad os apresentavam manchas brancas nas antenas.

Para as avaliações do comportamento de D. areolatus e A . anastrephae aos voláteis de frutos, foram utilizadas somente fêmeas acasaladas e inexperientes (5 a 7 dias de idade), sendo fixadas em álcool 70\% após o teste. 

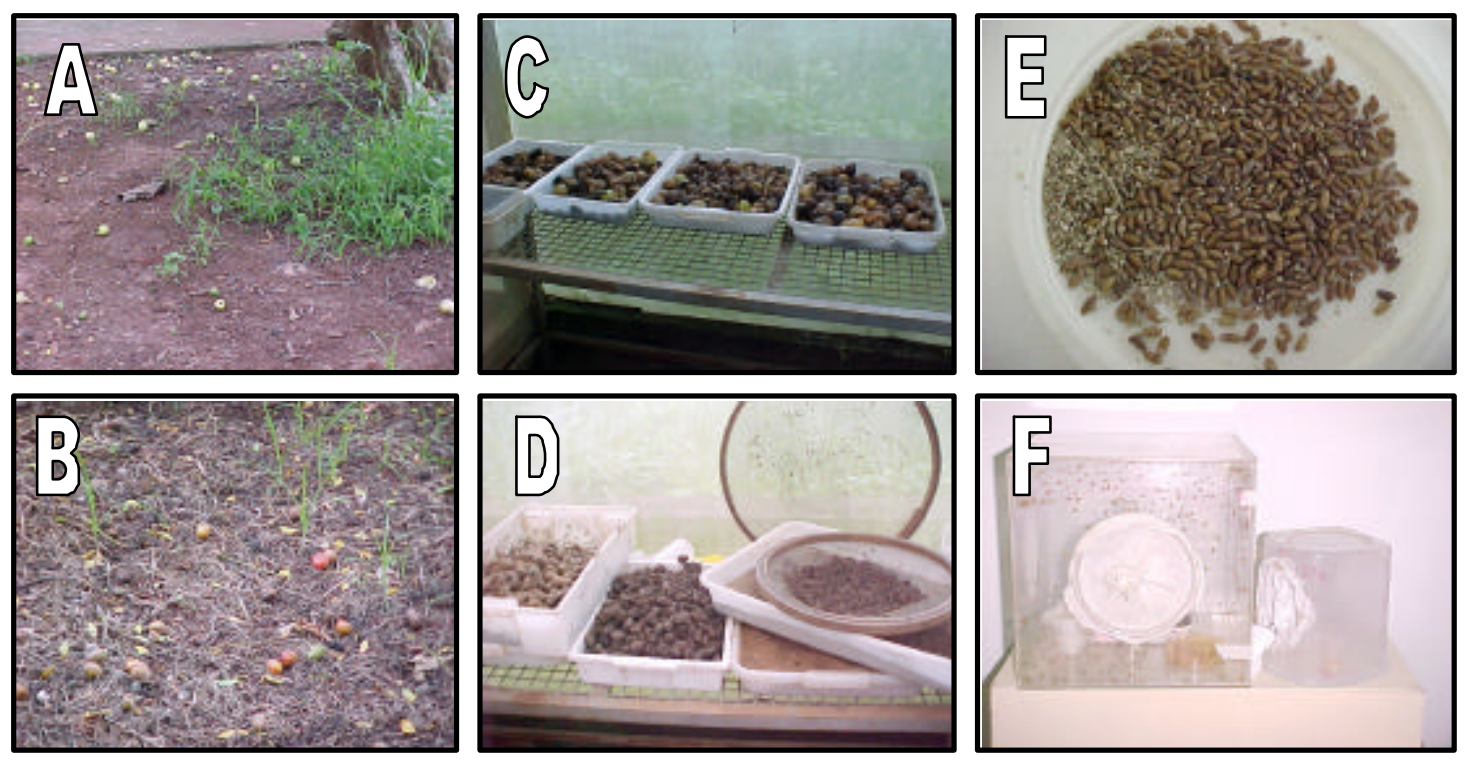

Figura 2 - Esquema de obtenção de parasitóides nativos. Coleta de frutos de goiaba (A) e sirigüela (B) sob a copa das árvores no campo; (C) Manutenção dos frutos em bandeja com vermiculita; (D) Peneiração dos frutos para separação das pupas; (E) Pupas de moscas-das-frutas após o peneiramento; (F) Gaiolas utilizadas para emergência das moscas-das-frutas e dos parasitóides (gaiola maior) e para manutenção dos parasitóides (gaiola menor). Temperatura de $25 \pm 5^{\circ} \mathrm{C}$, umidade relativa de $60 \pm 10 \%$ e luz natural

\subsection{0 btenção e manutenção de moscas-das-frutas}

\subsubsection{Ceratitis capitata}

As larvas recém-eclodidas da mosca-do-mediterrâneo foram obtidas da criação do CENA-USP e inoculadas em goiabas, a fim de se obter frutos com larvas de instares conhecidos. Foram inoculadas cerca de 15 larvas por fruto, em 
um total de 20 goiabas. Antes da inoculação, os frutos eram perfurados com agulha e as larvas colocadas próximas aos furos, de forma a facilitar a penetração. Foram utilizadas 15 larvas de C. capitata por fruto, em razão de uma avaliação prévia em goiabas coletadas no campo, ter demonstrado ser esse o número médio de larvas por fruto. Vale ressaltar, que a infestação dos frutos ocorreu em dias alternados de modo a suprir a necessidade do instar larval desejado no momento das avaliações.

Uma vez infestados, os frutos eram protegidos de eventuais infestações de outros insetos e mantidos em gaiola plástica de $15 \times 25 \mathrm{~cm}$ como descrito anteriormente, em sala com temperatura de $26 \pm 2^{\circ} \mathrm{C}$, umidade relativa de $60 \pm$ $10 \%$ e fotofase de 14 horas, no Laboratório de Biologia de Insetos da ESALQUSP.

Considerando-se que o desenvolvimento larval dura de 8 a 11 dias a $25^{\circ} \mathrm{C}$ (Morgante, 1991; Walder, 2002), estimou-se a média de cada instar de C. capitata em cerca de 3 dias, sendo assim possível manter um controle da idade das larvas a serem utilizadas nos bioensaios.

\subsubsection{Anastrepha fraterculus (Wied.)}

Inicialmente, as larvas de A. fraterculus foram obtidas a partir de quatro goiabas de uma criação do CENA-USP. Esses frutos foram acondicionados em uma bandeja plástica contendo vermiculita, conforme metodologia já descrita para a obtenção de parasitóides nativos (item 3.12). A pós cerca de 15 dias, as goiabas foram retiradas da bandeja e a vermiculita peneirada para a obtenção dos pupários de A fraterculus, que foram transferidas para uma gaiola de $50 \times 50$ cm confeccionada em alumínio e tela de voile com velcro ${ }^{\circledR}$ (Figura 3). A pós a emergência, 20 casais foram mantidos na gaiola para dar continuidade à criação, em sala a $25 \pm 2^{\circ} \mathrm{C}$, umidade relativa de $60 \pm 10 \%$ e fotofase de 14 horas (Salles, 
2000). A alimentação os adultos consistiu de água e dieta artificial a base de açúcar e proteína hidrolisada na proporção de 3:1, adaptado da metodologia de criação de C. capitata empregada no CEN A-USP (Walder, 2002).

Para a obtenção de goiabas infestadas por A. fraterculus, os frutos foram oferecidos às fêmeas férteis para oviposição por cerca de dois dias e após 48h da eclosão das larvas, foram considerados cerca de 3 dias de desenvolvimento larval para cada instar (Salles, 2000). Sendo assim, foram sempre utilizadas larvas de instares conhecidos para avaliação do comportamento olfativo dos parasitóides.

Para manutenção da criação, mamões (Carica papaya L.) em fase inicial de maturação foram oferecidos aos adultos de A . fraterculus, sendo que após cerca de três dias os frutos eram retirados e mantidos nas mesmas condições citadas para C. capitata (item 3.2.1). A pós cerca de 15 dias, os pupários eram separados e colocadas em placa de Petri, conforme descrito anteriormente (item 3.1.2).

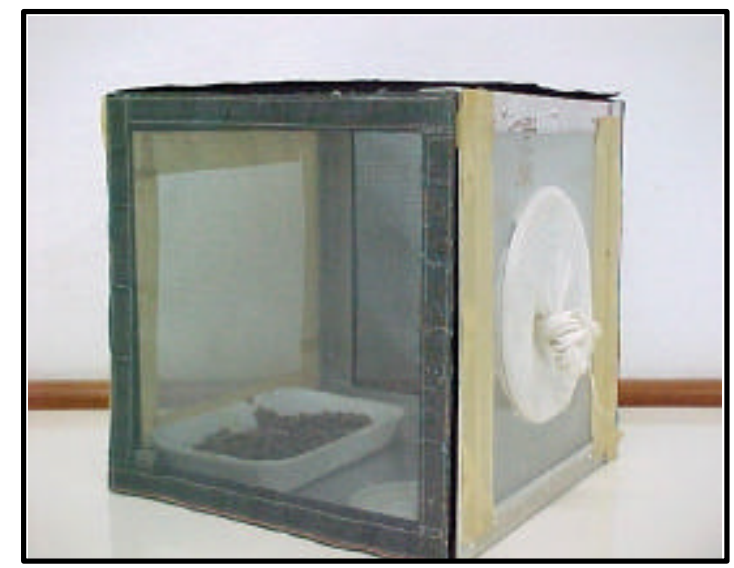

Figura 3 - Gaiola utilizada para criação e manutenção deA nastrepha fraterculus, em laboratório $\left(25 \pm 2^{\circ} \mathrm{C}\right.$, umidade relativa de $60 \pm 10 \%$ efotofase de 14 horas) 


\subsection{Resposta dos parasitóides aos voláteis}

Para os bioensaios de comportamento olfativo do parasitóide exótico D. longicaudata e dos parasitóides nativos D. areolatus e A. anastrephae aos frutos com e sem larvas de moscas-das-frutas, utilizou -se um olfatômetro de quatro vias, adaptado de Vet et al. (1983). Esse olfatômetro consiste de uma estrutura em acrílico na sua arena central, e quatro saídas laterais (braços) conectando três tubos de vidro a cada braço, onde são dispostos os tratamentos (Figura 4). A arena central é composta de quatro semicírculos de acrílico com (arco de 90, raio de $135 \mathrm{~mm}$ e altura de $20 \mathrm{~mm}$ ) colados sobre uma chapa de acrílico de 3,0 mm e uma cobertura móvel de acrílico transparente de 3,0 mm para visualização do comportamento do inseto aos voláteis testados (Figura 4B). A arena possui ainda, uma abertura na sua parte inferior de $8,0 \mathrm{~mm}$ de diâmetro, através da qual introduzia-se o inseto a ser testado e por onde se conectava a bomba de vácuo, para circular ar no sistema. As quatro saídas nas extremidades da arena também possuíam um orifício de $8,0 \mathrm{~mm}$ de diâmetro para a conexão dos braços.

Cada braço é composto de uma série de três tubos de vidro (50 ml) conectados entre si até a câmara central por mangueiras de silicone (Figura 4C). O primeiro tubo junto à câmara central tinha por finalidade capturar o inseto que respondia positivamente ao odor testado, ficando dessa forma sempre vazio; o segundo tubo continha a amostra a ser testada e o tubo distal apresentava água destilada para umedecer o ar no sistema. Em cada braço foi acoplado um fluxômetro para regular o fluxo do ar que entrava no sistema de forma harmônica (Figura 4D). O fluxo de ar foi obtido por meio da sucção proporcionada por uma bomba de vácuo acoplada ao orifício inferior da câmara central, por meio de uma mangueira plástica de PVC de $8,0 \mathrm{~mm}$ de diâmetro (Figura 4E). Adicionou-se ainda na saída do sistema um desumidificador de 
sílica gel para a retirada da umidade do ar, visando não comprometer o funcionamento da bomba de sucção (Figura 4E).

O fluxo de ar no olfatômetro foi calibrado por meio de um teste de fumaça, a partir da combinação de HCl + NH4OH (Vet et al., 1983; Hare, 1988), sendo a vazão do ar dentro do sistema definida em bioensaios preliminares em $300 \mathrm{ml} / \mathrm{min}$. A pós a distribuição das amostras nos respectivos braços, untava-se com vaselina a base superior da câmara central para maior aderência da tampa durante a sucção (bioensaio).

Para o início dos bioensaios, que consistia na introdução da fêmea dos parasitóides na arena, era necessário desconectar a mangueira na parte inferior da câmara central, introduzir a fêmea com auxílio de um frasco de vidro (15 x 46 $\mathrm{mm}$ ) e só então reconectar a mangueira para restabelecimento do vácuo no sistema.

O substrato utilizado como atraente foi goiaba nos estágios de maturação inicial (de vez) e de podridão, associada ou não às larvas de C. capitata e A. fraterculus. Foram utilizadas fêmeas de D. Iongicaudata (acasaladas, com quatro dias de idade), D . areolatus e A . anastrephae (acasaladas, com 7 a 10 dias de idade). Essa diferença de idades entre os parasitóides nativos e o exótico é devida à assincronia entre o momento da avaliação e a disposição das fêmeas dos parasitóides. Considerou-se cada fêmea como uma repetição, sendo estabelecido o tempo de resposta de no máximo 10 minutos (definido em bioensaios preliminares). O tempo de cada bioensaio foi controlado por meio de um cronômetro digital. 

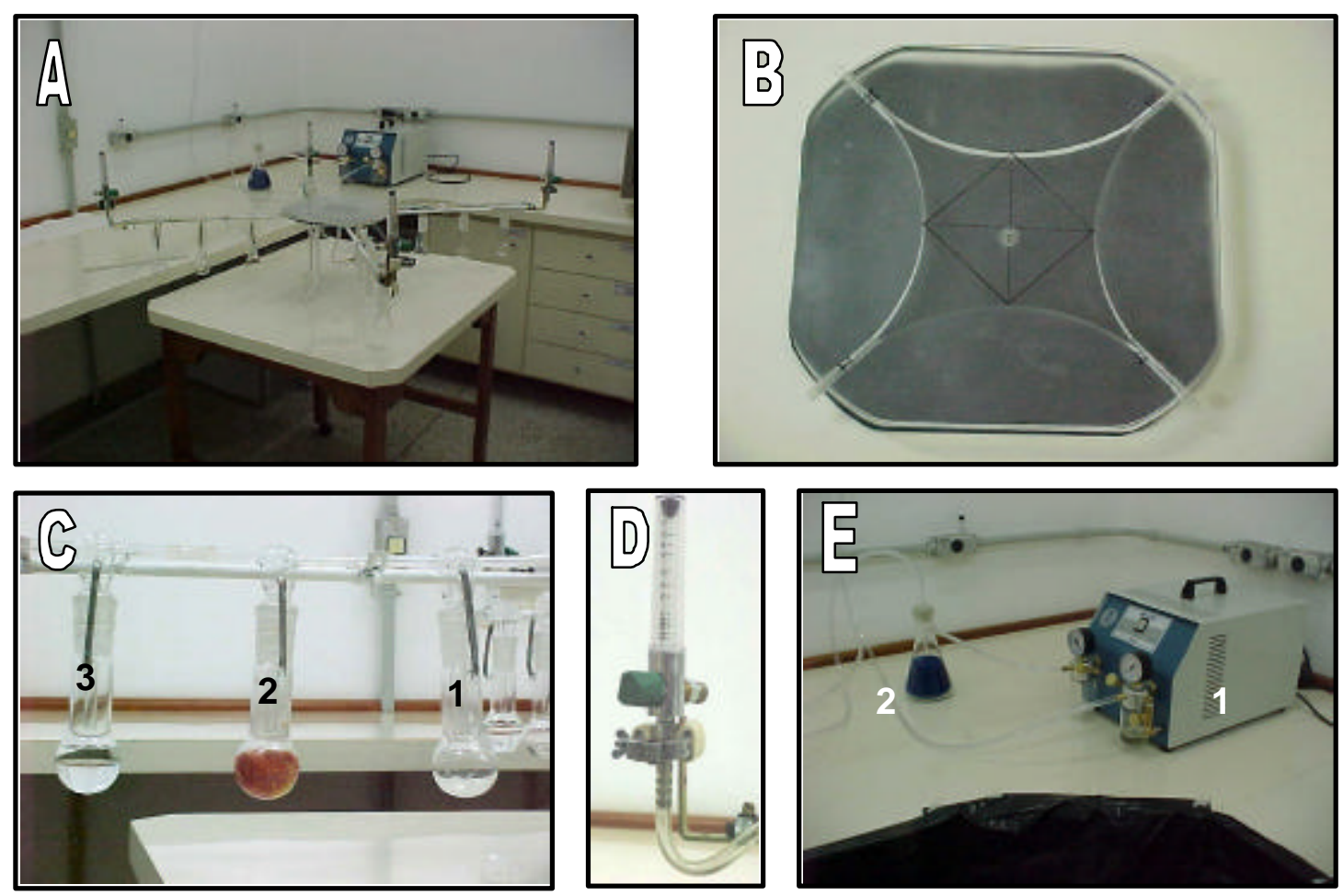

Figura 4 - Olfatômetro de quatro vias utilizado nos bioensaios com Diachasmimorpha Iongicaudata, D oryctobracon areolatus, A sobara anastrephae (A) Vista geral do aparelho; (B) Câmara central (vista superior); (C) Braço com detalhe (1- tubo vazio para coleta do parasitóide; 2 tubo com amostra-teste; 3- tubo com água destilada); (D) Fluxômetro; (E) Detalhe da bomba de vácuo (1) e do desumidificador desílica gel (2)

Para evitar uma possível interferência na resposta das fêmeas para um dos braços, o olfatômetro foi rotacionado em $90^{\circ}$ a cada repetição. As respostas comportamentais dos parasitóides foram determinadas a partir das observações de direcionamento, permanência nos respectivos campos de avaliação (I, II, III, IV) e entrada no tubo escolhido (tratamento), assim como primeira escolha e 
escolha final dos tratamentos. A cronometragem tinha início no momento em que o parasitóide cruzava uma das linhas arbitrárias que delimitavam os campos pertencentes aos tratamentos (linha de primeira escolha), anotando-se este tempo inicial e os tempos correspondentes a cada campo que o parasitóide visitava durante o período de aval iação.

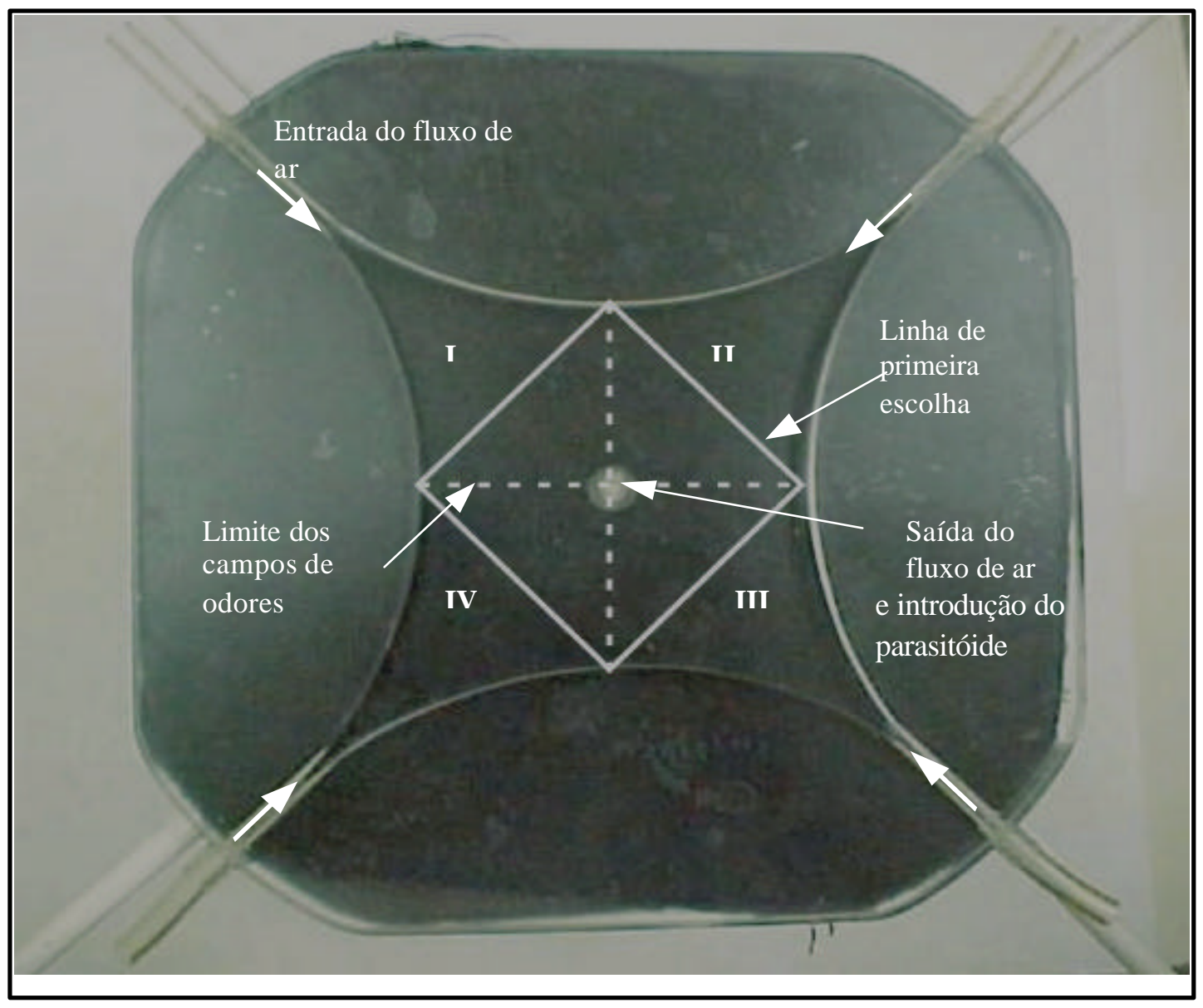

Figura 5 - Câmara central do olfatômetro (vista superior) com área central detalhando área em quadrado com suas linhas de primeira escolha para os tratamentos (I, II, III, IV), linhas de limite entre os campos de odores, direção do fluxo e abertura de saída do fluxo de ar e introdução do parasitóide 
Ao final do tempo de observação, registravase o campo onde o parasitóide se encontrava (escolha final). Caso o parasitóide penetrasse em um dos campos antes do tempo final, acrescentava-se o tempo restante ao quadrante escolhido eassim um novo teste era iniciado.

Cada bioensaio era constituído de quatro tratamentos, sendo realizadas 40 repetições (fêmeas) por bioensaio, onde cada fêmea foi utilizada uma única vez, evitando-se uma aprendizagem associativa. Os tratamentos utilizados variaram de acordo com o bioensaio nas quatro vias (I, II, III eIV).

Foram real izados os seguintes bioensaios:

Com D. Iongicaudata: (i) I, II, III e IV vazios (controle branco-branco); (ii) I com goiaba podre elI, III eIV vazios; (iii) I com goiaba podre, III com goiaba em maturação inicial (de vez) e II e IV vazios; (iv) I com goiaba com larvas de ?ִ instar de C. capitata e III com goiaba podre não infestada, e II e IV vazios; (v) I e III com goiaba podre com larvas de C. capitata de 1으 e 3을 instares, ell e IV vazios; e (vi) I com goiaba podre com larvas de 30 instar de C. capitata, e lll com goiaba podre com larvas de 3 o instar de A fraterculus, ell elV vazios.

Com D. areolatus: (i) I com goiaba podre, III com goiaba em maturação inicial (de vez), e II e IV vazios; (ii) I com goiaba podre com larvas de A. fraterculus em diferentes instares, III com goiaba podre não infestada, e II e IV vazios; (iii) I com goiaba podre com larvas de A. fraterculus em diferentes instares, III com goiaba podre com larvas de C. capitata em diferentes instares, e Il e IV vazios.

Com A. anastrephae: (i) I com goiaba podre infestada com larvas de A. fraterculus em diferentes instares, III com goiaba podre com larvas deC. capitata em diferentes instares, ell e IV vazios.

Os bioensaios ocorreram sempre das 9:00 às 17:00 horas, e após cada dia, o olfatômetro era desmontado e sua arena central, tubos e conexões lavados com detergente neutro (5\%) e desinfetados com ál cool 90\% (Vet et al., 1983). 


\subsection{A valiação em telado}

Para confirmar os dados obtidos em olfatômetro, foram realizadas liberações de fêmeas de $D$. longicaudata e de $D$. areolatus sem experiência prévia aos frutos ou larvas, em área telada $(6,0 \times 3,5 \times 3,0 \mathrm{~m})$. Foram utilizadas gaiolasarmadilhas visando à captura de fêmeas a uma determinada fonte de odor (Figura 6). As armadilhas foram feitas de garrafas plásticas "Pet" cortadas na altura de $2 / 3$ e os frutos infestados ou não (tratamentos) eram colocados no seu interior. A parte superior da gaiola-armadilha era coberta com "magipack" e com uma placa cerâmica de $12 \times 12 \mathrm{~cm}$ para dar peso e evitar um possível tombamento. Foram recortadas quatro aberturas de $2,0 \times 4,0 \mathrm{~cm}$, uma de cada lado da gaiola-armadilha para a entrada do parasitóide. Na parede interna da gaiola-armadilha, foi adicionada uma cola adesiva ("stick") para a coleta dos insetos atraídos.

Os tratamentos utilizados foram: (i) goiaba em estágio inicial de maturação (de vez) sem larvas de mosca-das-frutas; (ii) goiaba podre sem larvas de moscas-das-frutas; (iii) goiaba podre com larvas de C. capitata; (iv) goiaba podre com larvas de A . fraterculus; e (v) controle (branco). As gaiolas-armadilhas foram distribuídas ao acaso no chão do telado com eqüidistância de $50 \mathrm{~cm}$. Foram realizadas quatro repetições por tratamento durante quatro dias, espaçados de uma semana. Foram liberados 100 indivíduos por vez de D. longicaudata (de 4 dias) e D. areolatus (de 7 dias). Avaliou-se o comportamento das fêmeas dos parasitóides por um período de 24 horas, quando as gaiolas armadilhas foram retiradas e os parasitóides capturados quantificados. 

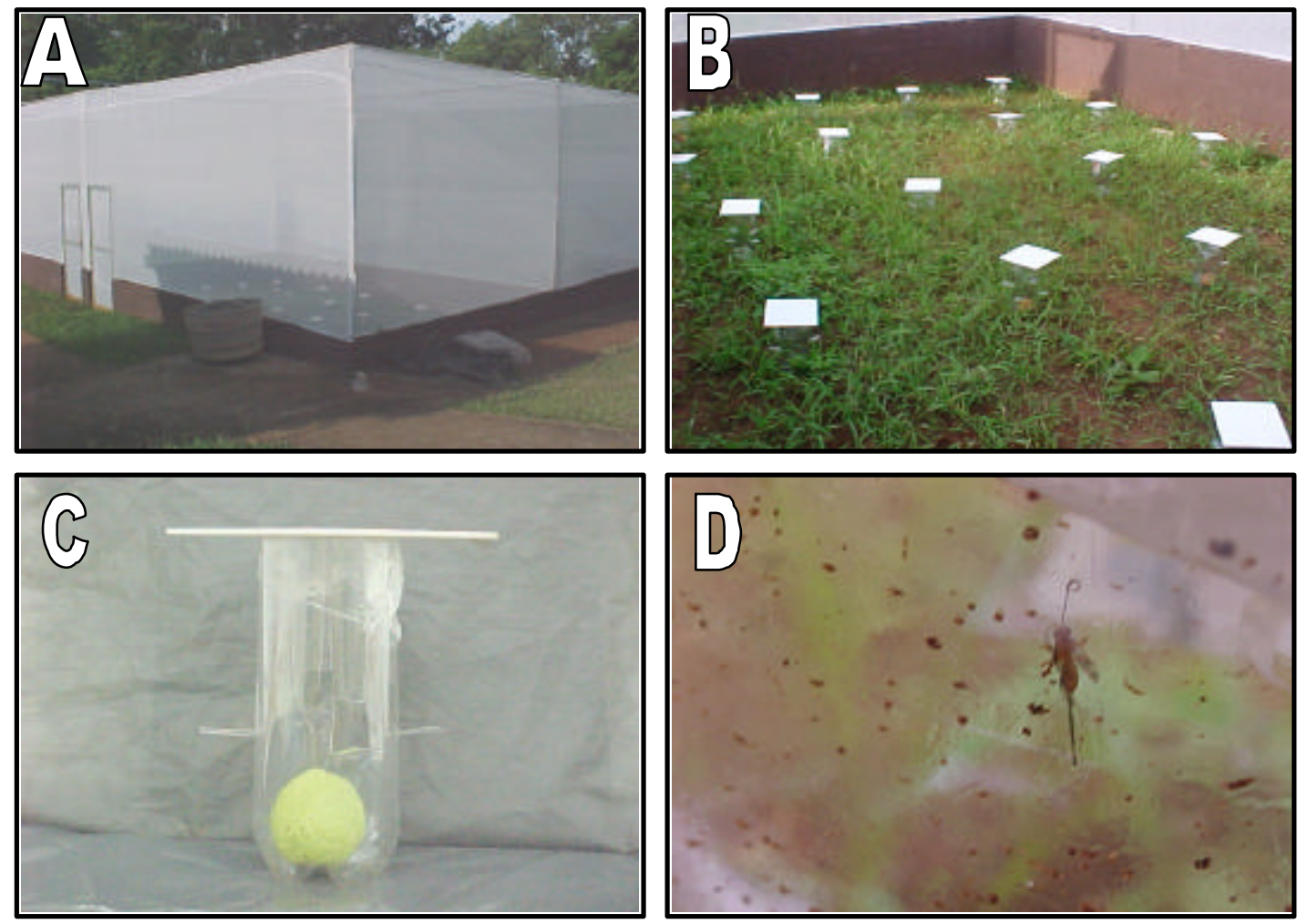

Figura 6 - Avaliação do comportamento de D. Iongicaudata em telado. (A) Á rea telada para avaliação do comportamento olfativo de $D$. Iongicaudata; (B) Detalhe da distribuição dos tratamentos no interior do telado; (C) Detalhe de uma gaiola-armadilha; e (D) Parasitóide capturado em gaiola-armadilha

\subsection{A nálises Estatísticas}

Os dados referentes à permanência dos parasitóides nos respectivos quadrantes do olfatômetro (escolha) foram convertidos em percentagem. Para calcular as diferenças entre os campos de escolha, os dados foram submetidos a análise de variância a partir do teste de Kruskall-Wallis (Hare, 1988). Os dados 
de primeira escolha e escolha final foram submetidos a um teste de quiquadrado (Sokal \& Rohlf apud Hare, 1988). As análises foram efetuadas por meio do programa "BioEstat" versão 1.0 para Windows.

Os dados obtidos na liberação de parasitóides em área coberta (telado), foram submetidos à análise de variância conforme Messing \& Jang (1992), utilizando-se o teste de Kruskall-Wallis (Hare, 1988). As análises foram efetuadas por meio do programa "BioEstat" versão 1.0 para Windows. 


\section{RESULTADOS E DISCUSSÃO}

\subsection{Resposta olfativa}

\subsubsection{Resposta olfativa de D. Iongicaudata aos voláteis de goiaba podre.}

As fêmeas de D. Iongicau data apresentaram al ta capacidade de reconhecer e explorar voláteis de goiaba podre. Os dados de primeira escolha e de escolha final do parasitóide no olfatômetro sugerem uma resposta positiva aos voláteis de goiaba podre, mesmo na ausência de larvas de moscas-das-frutas (Tabela 1).

Considerando-se o tempo de permanência nos respectivos campos de exposição aos voláteis do olfatômetro, notase D. Iongicaudata possui alta capacidade exploratória. As fêmeas passaram em média mais de 15\% do seu tempo explorando ao menos um dos quatro campos de voláteis, com uma preferência acentuada para goiaba podre (41\%), embora esses dados não tenham diferido significante do campo em branco (24\%). 
Tabela 1. Resposta olfativa de fêmeas de D iachasmimorpha longicaudata a voláteis de goiaba podre $(n=40)$

\begin{tabular}{cccc}
\hline Tratamentos & $\begin{array}{c}\text { 1a escolhas* }^{*} \\
(\mathrm{n})\end{array}$ & $\begin{array}{c}\text { Escolhas finais** } \\
(\mathrm{n})\end{array}$ & Tempo médio (\%)*** \\
\hline Goiaba podre & 18 & 17 & $41.28 \pm 2,54 \mathrm{a}$ \\
Branco & 7 & 12 & $24.19 \pm 3,84 \mathrm{ab}$ \\
Branco & 6 & 7 & $15.56 \pm 3,66 \mathrm{~b}$ \\
Branco & 9 & 4 & $18.97 \pm 1,42 \mathrm{~b}$
\end{tabular}

* Teste de qui-quadrado ( $\mathrm{P}=0,0293)$; ** Teste de qui-quadrado ( $\mathrm{P}=0,0203)$; ***Valores seguidos da mesma letra na coluna não diferem entre si pelo teste de Kruskall-Wallisa $5 \%$ de probabilidade.

\subsubsection{Resposta olfativa de D. longicaudata e D. areolatus a voláteis de goiaba em maturação inicial (de vez) e podre.}

Confrontando-se as goiabas em maturação inicial (de vez) e podres, notou-se que as fêmeas de D. Iongicaudata demonstraram forte preferência em explorar os voláteis de goiaba podre (47\%) em relação aos demais tratamentos (Tabela 2), confirmando os resultados do primeiro bioensaio (Tabela 1).

As fêmeas de D. areolatus, por sua vez, demonstraram serem capazes de explorar tanto os odores de frutos podres (39\%) quanto os de vez (26\%), embora neste último caso, não tenha diferido significativamente de um dos campos em branco (19\%) (Tabela 3).

Considerando-se os dados de primeira escolha e escolha final para os diferentes campos de voláteis no olfatômetro, notou-se uma preferência significativa de D. Iongicaudata para o campo com goiaba podre (Tabela 2), enquanto para $D$. areolatus, não houve uma preferência por nenhum dos campos (Tabela 3). 
Tabela 2. Resposta olfativa de fêmeas de D iachasmimorpha longicaudata a voláteis de goiaba em maturação inicial (de vez) e podre $(n=40)$

\begin{tabular}{|c|c|c|c|}
\hline Tratamentos & $\begin{array}{c}\text { 19a escolhas* } \\
\text { (n) }\end{array}$ & $\begin{array}{c}\text { Escolhas finais** } \\
\text { (n) }\end{array}$ & $\begin{array}{c}\text { Tempo médio (\%) no } \\
\text { quadrante*** }\end{array}$ \\
\hline Goiaba podre & 18 & 25 & $47.85 \pm, 06 a$ \\
\hline Branco & 6 & 7 & $15.84 \pm, 00 \mathrm{~b}$ \\
\hline $\begin{array}{l}\text { Goiaba em matura } \\
\text { inicial (de vez) }\end{array}$ & 9 & 5 & 21.87\#,69ab \\
\hline Branco & 7 & 3 & $14.44 \pm 4,52 b$ \\
\hline
\end{tabular}

Os resultados obtidos para ambas as espécies sugerem que estes parasitóides utilizam os voláteis de frutos podres como uma das fontes de orientação ao hábitat de seu hospedeiro. Além disso, comparativamente, D. areolatus possui maior leque de exploração em relação a $D$. Iongicaudata, pois o seu comportamento olfativo inclui ainda os odores de frutos em maturação inicial (de vez), o que poderia conferir uma vantagem adaptativa para esta espécie. 
Tabela 3. Resposta olfativa de fêmeas de D oryctobracon areolatus a voláteis de goiaba em maturação inicial (de vez) e podre. $(n=40)$

\begin{tabular}{cccc}
\hline Tratamentos & $\begin{array}{c}1^{\text {a }} \text { escolhas* } \\
(\mathrm{n})\end{array}$ & $\begin{array}{c}\text { Escolhas finais** } \\
(\mathrm{n})\end{array}$ & Tempo médio (\%)**** \\
\hline Goiaba podre & 15 & 16 & $39.32 \pm 8,70 \mathrm{a}$ \\
Branco & 7 & 5 & $14.89 \pm 3,92 \mathrm{c}$ \\
$\begin{array}{c}\text { Goiaba em maturação } \\
\text { inicial (de vez) }\end{array}$ & 9 & 7 & $26.30 \pm 3,56 \mathrm{ab}$ \\
Branco & 9 & 7 & $19.49 \pm 2,76 \mathrm{bc}$
\end{tabular}

* Teste de qui-quadrado ( $P=0,3080)$; ** Teste de qui-quadrado ( $P=0,0600)$; *** Valores seguidos da mesma letra na coluna, não diferem entre si pelo teste de Kruskall-Wallis a $5 \%$ de probabilidade.

\subsubsection{Resposta olfativa de D. Iongicaudata e D. areolatus a voláteis de goiabas podres com e sem larvas de moscas-das-frutas}

Uma vez verificada a orientação de D. Iongicau data e D . areolatus a voláteis de frutos em estado de podridão, comparou-se o comportamento olfativo de ambas espécies de parasitóides para frutos com e sem larvas de moscas-dasfrutas.

As fêmeas de $D$. Iongicaudata apresentaram alta capacidade de reconhecer os voláteis de goiabas podres com larvas de 3 o instar de C. capitata (Tabela 4). As larvas nos frutos podres liberam ou induzem à formação de voláteis bastante atrativos a este parasitóide quando comparado aos frutos podres não-infestados. Este comportamento já havia sido demonstrado como importante na local ização de larvas de moscas-das-frutas por outras espécies de parasitóides, incluindo $D$. Iongicaudata (Greany et al., 1977; Leyva et al., 1991; Messing \& Jang, 1992; Jang et al., 2000). 
Tabela 4. Resposta olfativa de fêmeas de D iachasmimorpha longicaudata a voláteis de goiaba podre com e sem larvas de $\mathfrak{P}$ instar de Ceratitis capitata $(n=40)$

\begin{tabular}{|c|c|c|c|}
\hline Tratamentos & $\begin{array}{c}\text { 1" escolhas* }^{\text {a es }} \\
\text { (n) }\end{array}$ & $\begin{array}{c}\text { Escolhas finais** } \\
\text { (n) }\end{array}$ & $\begin{array}{c}\text { Tempo médio } \\
\text { (\%)*** }\end{array}$ \\
\hline $\begin{array}{c}\text { Goiaba podre com larvas de 30- } \\
\text { instar de C. capitata }\end{array}$ & 16 & 22 & $40,91 \pm 2,36 a$ \\
\hline Branco & 6 & 6 & $20,49 \pm 2,37 b c$ \\
\hline Goiaba podre não-infestada & 10 & 9 & $24,68 \pm 2,53 b$ \\
\hline Branco & 8 & 3 & $13,93 \pm 4,74 \mathrm{c}$ \\
\hline
\end{tabular}

* Teste de qui-quadrado ( $P=0,1328)$; ** Teste de qui-quadrado ( $P=0,0001)$; *** Valores seguidos da mesma letra na coluna não diferem entre si pelo teste de Kruskall-Wallisa $5 \%$ de probabilidade.

Os resultados de primeira escolha no olfatômetro demonstraram ainda que D. Iongicaudata, como nos bioensaios anteriores, apresentou grande capacidade exploratória, uma vez que não houve influência dos tratamentos nesta etapa (Tabela 4). Os dados da escolha final no olfatômetro confirmam que para este parasitóide, a presença de larvas de C. capitata nos frutos podres, influenciou significativamente a sua resposta.

De modo semel hante, as fêmeas de $D$. ar eol atus também foram capazes de reconhecer e selecionar significativamente goiabas podres com larvas de diferentes instares de A. fraterculus, quando comparados com goiabas podres não-infestados (Tabela 5). Resultado semelhante para este parasitóide em pêras com larvas de A nastrepha su spensa (Loew) também foi observado por Eitam et al. (2003). 
Tabela 5. Resposta olfativa de fêmeas de D oryctobracon areolatus a voláteis de goiaba podre om e sem larvas de 끄 a 3 o instares de A nastrepha fraterculus. $(n=40)$

\begin{tabular}{|c|c|c|c|}
\hline Tratamentos & $\begin{array}{c}\text { 1a escolhas* }^{*} \\
\text { (n) }\end{array}$ & $\begin{array}{l}\text { Escolhas } \\
\text { finais** } \\
\text { (n) }\end{array}$ & $\begin{array}{c}\text { Tempo médio } \\
\text { (\%)*** }\end{array}$ \\
\hline \multicolumn{4}{|l|}{ Goiaba podre com larvas de } \\
\hline A. fraterculus & 15 & 20 & $43,23 \pm 14,29 a$ \\
\hline Branco & 9 & 8 & $18,77 \pm 7,23 b$ \\
\hline Goiaba podre não-infestada & 11 & 5 & $21,77 \pm 14,90 b$ \\
\hline Branco & 5 & 7 & $16,74 \pm 4,18 b$ \\
\hline
\end{tabular}

* Teste de qui-quadrado ( $\mathrm{P}=0,1577)$; ** Teste de qui-quadrado $(\mathrm{P}=0,0032)$; *** Valores seguidos da mesma letra na coluna não diferem entre si pelo teste de Kruskall-Wallisa $5 \%$ de probabilidade.

Os dados de primeira escolha no olfatômetro demonstraram não haver diferença significativa entre os tratamentos, sugerindo que $D$. areolatus explora inicialmente tanto voláteis de frutos infestados como de não-infestados (Tabela 5). Para a escolha final, houve diferença significativa entre os tratamentos, com uma forte preferência por goiabas podres com larvas deA . fraterculus.

\subsubsection{Resposta olfativa de D. longicaudata a voláteis de goiaba com larvas de Ceratitis capitata em diferentes idades}

As fêmeas de $D$. Iongicaudata não foram capazes de diferenciar significativamente entre goiabas podres com larvas de ㄲo e ֵㅡ instares daqueles com larvas de P instar de C. capitata (Tabela 6). Este resultado sugere que este parasitóide utiliza outros mecanismos além do químico, no processo de 
reconhecimento do instar larval mais adequado para o parasitismo de larvas de moscas-das-frutas. De acordo com Clausen (1956), o 30 instar larval de moscasdas-frutas seria o preferido por $D$. Iongicaudata. N este caso, o parasitóide seria atraído por voláteis dos frutos em podridão contendo larvas de moscas-dasfrutas, porém a aceitação do hospedeiro ocorreria já sobre o fruto, por meio de vibrotaxia, fato este já demonstrado para diversas espécies de parasitóides de moscas-das-frutas (Lawrence, 1981; Glas \& Vet, 1983; Carvalho \& Nascimento 2002; Carvalho, 2003; Guimarães \& Zucchi, 2004). Além disso, D. Iongicaudata apresenta o hábito de forragear frutos já caídos ao solo e podres (em fermentação) (Greany et al., 1977; Leyva et al., 1991; Messing \& Jang, 1992; Purcell et al., 1994). Com isso, haveria grande possibilidade de D. Iongicaudata encontrar larvas no 3 - instar de moscas-das-frutas para serem parasitadas.

Os resultados de primeira escolha e escol ha final no olfatômetro indicam que também há diferença significativa entre os tratamentos, principalmente entre os tratamentos com frutos podres (com e sem larvas) comparados ao controle (branco), demonstrando uma rápida e eficiente orientação do parasitóide neste bioensaio (Tabela 6). 
Tabela 6. Resposta olfativa de fêmeas de D iachasmimorpha longicaudata a voláteis de goiaba podre com larvas de 1으e 2응 instares e com larvas de 3ㅇinstar de Ceratitis capitata. $(n=40)$

\begin{tabular}{|c|c|c|c|}
\hline Tratamentos & $\begin{array}{c}\text { 19a escolhas* } \\
\text { (n) }\end{array}$ & $\begin{array}{l}\text { Escolhas finais** } \\
\qquad(\mathrm{n})\end{array}$ & $\begin{array}{c}\text { Tempo médio } \\
\text { (\%)**** }\end{array}$ \\
\hline Goiaba podre com larvas de 3으 & & & \\
\hline instar de C. capitata & 12 & 13 & $32,00 \pm 7,93 a b$ \\
\hline Branco & 6 & 2 & $9,46 \pm 5,12 c$ \\
\hline 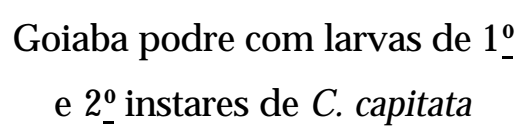 & 18 & 18 & $44,02 \pm 3,37 a$ \\
\hline Branco & 4 & 7 & $14,52+4,80 \mathrm{bc}$ \\
\hline
\end{tabular}

* Teste de qui-quadrado ( $P=0,0074)$; ** Teste de qui-quadrado $(P=0,0022)$; *** Valores seguidos da mesma letra na coluna não diferem entre si pelo teste de Kruskall-Wallisa $5 \%$ de probabilidade.

\subsubsection{Resposta olfativa de D. Iongicaudata, D. areolatus e A. anastrephae a voláteis de goiaba com larvas de $C$. capitata e A. fraterculus}

As fêmeas de $D$. Iongicaudata não demonstraram preferência significativa do ponto de vista de atratividade entre C. capitata ou A fraterculus (Tabela 7). $\mathrm{O}$ tempo de permanência deste parasitóide em ambos os campos dessas duas espécies foi semelhante (37 e 36\%, respectivamente). Considerando-se a escolha do parasitóide no olfatômetro, não houve diferença significativa entre os tratamentos, porém, na escolha final, os tratamentos contendo as larvas de moscas-das-frutas foram os de maior resposta comparado ao controle. 
Tabela 7. Resposta olfativa de fêmeas de D iachasmimorpha longicaudata a voláteis de goiaba podre com larvas de diferentes instares de Ceratitis capitata e A nastrepha fraterculus. $(\mathrm{N}=40)$

\begin{tabular}{|c|c|c|c|}
\hline Tratamentos & $\begin{array}{c}1^{\underline{a}} \text { escolhas* } \\
(n)\end{array}$ & $\begin{array}{l}\text { Escolhas finais** } \\
\qquad(\mathrm{n})\end{array}$ & $\begin{array}{l}\text { Tempo médio } \\
\text { (\%)***k }\end{array}$ \\
\hline $\begin{array}{c}\text { Goiaba podre com larvas } \\
\text { deC. capitata }\end{array}$ & 9 & 19 & $37,88 \pm 5,50 a$ \\
\hline Branco & 8 & 3 & $14,14 \pm 2,96 b$ \\
\hline $\begin{array}{c}\text { Goiaba podre com larvas } \\
\text { de A . fraterculus }\end{array}$ & 16 & 14 & $36,26 \pm 5,77 a$ \\
\hline Branco & 7 & 4 & $11,72 \pm 5,93 b$ \\
\hline
\end{tabular}

A resposta das fêmeas de $D$. areolatus aos tratamentos contendo larvas de C. captitata e A. fraterculus, por sua vez, foi mais específica do que o observado para D. Iongicaudata. As fêmeas de D. areolatus apresentaram uma preferência significativa por goiabas com larvas de A . fraterculus, em relação às goiabas com larvas de C. capitata (Tabela 8). D. areolatus é um parasitóide amplamente distribuído na região Neotropical (Wharton \& Marsh, 1978). No Brasil, é considerado espécie dominante, presente em 62 a 89\% do total de parasitóides nos levantamentos das espécies de A nastrepha (ver Eitam et al., 2003). Assim, aparentemente, haveria estreito processo co-evolutivo entre estas duas espécies (hospedeiro-parasitóide), o que explicaria a resposta mais eficiente de D. areolatus na presença de larvas de A. fraterculus, em detrimento da espécie exótica, C. capitata. 
Embora ainda não se conheça o estádio larval de A . fraterculus eC. capitata mais propício para o parasitismo de D. areolatus, este parasitóide é freqüentemente encontrado parasitando larvas em frutos ainda na planta (Matrangolo et al., 1998; Sugayama, 2000; Aguiar-Menezes \& Menezes, 2001), o que indicaria que estádios larvais abaixo do 3 - instar estariam aptos ao parasitismo, diferentemente do observado para D. Iongicaudata. Neste sentido, D . areolatus possui capacidade de explorar frutos ainda em maturação ini cial (de vez), como foi observado anteriormente (Tabela 3). Portanto, a estratégia de forrageamento utilizada por D. areolatus poderia conferir uma vantagem adaptativa sobre D. Iongicaudata, o que justificaria ao menos em parte os altos índices de parasitismo observados em condições naturais.

Os dados de primeira escolha no olfatômetro demonstraram não haver diferença significativa entre os tratamentos, sugerindo que D. areolatus explora inicialmente voláteis de frutos infestados tanto com A. fraterculus quanto com C. capitata, porém para escolha final, houve uma preferência significativa por frutos podres com larvas de A . fraterculus (Tabela 8). 
Tabela 8. Resposta olfativa de fêmeas de Doryctobracon areolatus a voláteis de goiaba podre com larvas de diferentes instares de Ceratitis capitata e A nastrepha fraterculus. $(n=40)$

\begin{tabular}{cccc}
\hline Tratamentos & $\begin{array}{c}1^{\text {a }} \text { escolhas* } \\
\text { (n) }\end{array}$ & $\begin{array}{c}\text { escolhas finais** } \\
\text { (n) }\end{array}$ & $\begin{array}{c}\text { Tempo médio } \\
(\%) * * *\end{array}$ \\
\hline $\begin{array}{c}\text { Goiaba podre com larvas } \\
\text { de A. fraterculus }\end{array}$ & 16 & 19 & $42,69 \pm 5,76 \mathrm{a}$ \\
Branco & 8 & 2 & $13,13 \pm 6,43 \mathrm{c}$ \\
$\begin{array}{c}\text { Goiaba podre com larvas } \\
\text { de C. capitata }\end{array}$ & 11 & 15 & $32,65 \pm 3,71 \mathrm{~b}$ \\
Branco & 5 & 4 & $11,53 \pm 4,97 \mathrm{c}$ \\
\hline
\end{tabular}

* Teste de qui-quadrado ( $\mathrm{P}=0,0858)$; ** Teste de qui-quadrado $(\mathrm{P}=0,0001)$; *** Valores seguidos da mesma letra na coluna não diferem entre si pelo teste de Kruskall-Wallisa $5 \%$ de probabilidade.

A . anastrephae não apresentou preferência por goiabas com larvas de A. fraterculus ou de $\mathrm{C}$. capitata (Tabela 9). Porém, nota-se que houve diferença significativa entre os tratamentos na primeira escolha e na escolha final no olfatômetro para os frutos com larvas de moscas-das-frutas. Portanto, observa se que A . anastrephae explora os voláteis de frutos podres com larvas de moscasdas-frutas eficientemente. Há poucas informações sobre este parasitóide na literatura, incluindo sua eficiência e preferência pelas diferentes espécies de moscas-das-frutas, o que dificulta a aval iação dos resultados obtidos. Esse fato é de interesse, pois A . anastrephae pertence à subfamília Allysinae, entretanto, os estudos têm sido conduzidos principal mente com os representantes de Opiinae, onde se encontra D. Iongicaudata e D. areolatus. 
Tabela 9. Resposta olfativa de fêmeas de A sobara an astrephae a voláteis de goiaba podre com larvas de diferentes instares de Ceratitis capitata e A nastrepha fraterculus. $(n=40)$

\begin{tabular}{cccc}
\hline Tratamentos & $\begin{array}{c}\text { 10 escolhas* } \\
(\mathrm{n})\end{array}$ & $\begin{array}{c}\text { Escolhas finais** } \\
(\mathrm{n})\end{array}$ & $\begin{array}{c}\text { Tempo médio } \\
(\%) * * *\end{array}$ \\
\hline $\begin{array}{c}\text { Goiaba podrecom larvas } \\
\text { de A. fraterculus }\end{array}$ & 13 & 20 & $38,89 \pm 4,27 \mathrm{a}$ \\
Branco & 8 & 2 & $17,68 \pm 4,33 \mathrm{~b}$ \\
$\begin{array}{c}\text { Goiaba podrecom larvas } \\
\text { deC. capitata }\end{array}$ & 12 & 16 & $33,55 \pm 2,26 \mathrm{a}$ \\
Branco & 7 & 2 & $9,87 \pm 6,50 \mathrm{~b}$ \\
\hline
\end{tabular}

* Teste de qui-quadrado ( $\mathrm{P}=0,4575)$; ** Teste de qui-quadrado $(\mathrm{P}=0,0001)$; *** Valores seguidos da mesma letra na coluna não diferem entre si pelo teste de Kruskall-Wallisa $5 \%$ de probabilidade.

\subsubsection{Controle branco $x$ branco}

Verificou-se a ausência de qualquer tendência de $D$. Iongicaudata a um dos campos do olfatômetro nos bioensaios de controle (branco $\mathrm{x}$ branco). Os dados

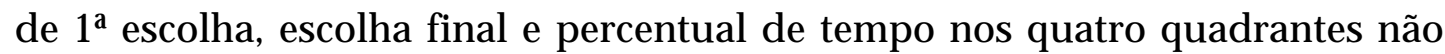
apresentaram diferença significativa entre os tratamentos, indicando que o sistema utilizado foi eficiente na discriminação dos voláteis pelos parasitóides estudados (Tabela 10). 
Tabela 10. Resposta olfativa de fêmeas de Diachasmimorpha longicaudata aos diferentes quadrantes em branco (controle) do olfatômetro de quatro vias. $(\mathrm{N}=20)$

\begin{tabular}{cccc}
\hline Tratamentos & $\begin{array}{c}1^{\text {a }} \text { escolhas* } \\
(\mathrm{n})\end{array}$ & $\begin{array}{c}\text { escolhas finais** } \\
(\mathrm{n})\end{array}$ & $\begin{array}{c}\text { Tempo médio } \\
(\%)^{* * *}\end{array}$ \\
\hline Branco & 7 & 7 & $25.94 \pm 4,17 \mathrm{a}$ \\
Branco & 7 & 3 & $23.75 \pm 3,89 \mathrm{a}$ \\
Branco & 1 & 5 & $26.34 \pm 2,70 \mathrm{a}$ \\
Branco & 5 & 5 & $23.97 \pm 0,58 \mathrm{a}$ \\
\hline
\end{tabular}

* Teste de qui-quadrado ( $P=0,1870)$; ** Teste de qui-quadrado $(P=0,6594)$; *** Valores seguidos da mesma letra na coluna não diferem entre si pelo teste de Kruskall-Wallisa $5 \%$ de probabilidade.

\subsubsection{Comportamento olfativo de $D$. Iongicaudata e $D$. areolatus em telado}

As fêmeas de D. Iongicaudata demonstraram alta capacidade para o forrageamento de goiabas podres no solo (Tabela 11). As capturas nas armadilhas indicaram que não houve diferença significativa entre a atratividade de frutos podres com larvas de C. capitata ou de A. fraterculus. Também frutos podres com larvas de A. fraterculus não diferiram significativamente de frutos podres sem larvas de moscas-das-frutas. Por outro lado, houve diferença significativa entre goiabas podres com larvas de C. capitata comparado aos frutos podres sem larvas de moscas-das-frutas. Assim, aparentemente, D. Iongicaudata tem tendência a parasitar preferencialmente frutos com C. capitata, no entanto, essa inferência precisa ser comprovada. De qualquer forma, o fato de haver uma diferença significativa entre os tratamentos contendo frutos podres em relação aos frutos de vez, sugere que os frutos podres são realmente 
cruciais para D. Iongicautada no processo de seleção do hospedeiro, conforme demonstrado anteriormente (Tabelas 1 e 2).

Para D . areolatus não houve captura de nenhum indivíduo nas armadilhas com goiabas em diferentes estágios de maturação, com ou sem larvas de moscas-das-frutas (Tabela 11). Este resultado sugere que D. areolatus dificilmente forrageia em frutos caídos, como seria esperado nas condições desse experimento. Foi observado, por exemplo, um grande número de fêmeas de D. areolatus na parte superior do telado, sem descer ao solo durante o experimento. Isto poderia indicar, que em condições naturais este parasitóide realmente tenha o hábito de forragear somente na parte área das plantas. De acordo com Matrangolo et al. (1988) e Aguiar-Menezes (2002), o nicho de forrageamento de espécies de opíineos nativos, como no caso de D. areolatus, difere daqueles explorados pelo parasitóide exótico $D$. Iongicautada, uma vez que D. areolatus realiza o seu parasitismo em frutos com diferentes estágios de maturação ainda na planta, enquanto D. Iongicaudata realiza preferencialmente no solo (frutos podres). Entretanto, estes resultados não são conclusivos e em experimentos futuros, sugere-se a instalação dessas armadilhas na parte superior do telado ou, empregando armadilhas em condições de campo tanto no solo como na planta. 
Tabela 11. Resposta olfativa de fêmeas dos parasitóides Diachasmimorpha longicaudata e Doryctobracon areolatus a voláteis de goiaba em maturação inicial (de vez) e podre com e sem larvas de Ceratitis capitata e A nastrepha fraterculus em armadilhas instaladas dentro de telado

D iachasmimorpha longicaudata D oryctobracon areolatus

\begin{tabular}{|c|c|c|c|c|}
\hline Tratamentos & $\begin{array}{c}\% \text { de } \\
\text { resposta* }\end{array}$ & $\begin{array}{l}\text { Número médio } \\
\text { de insetos } \\
\text { capturados por } \\
\text { armadilha }\end{array}$ & $\begin{array}{c}\% \text { de } \\
\text { resposta }\end{array}$ & $\begin{array}{l}\text { Número médio } \\
\text { deinsetos } \\
\text { capturados por } \\
\text { armadilha }\end{array}$ \\
\hline $\begin{array}{c}\text { Goiaba em maturação } \\
\text { inicial (de vez) }\end{array}$ & $2,0 \pm 1,0 \mathrm{C}$ & 0,5 & 0,0 & 0,0 \\
\hline Goiaba podre & $26,0 \pm 6,40 b$ & 6,5 & 0,0 & 0,0 \\
\hline $\begin{array}{c}\text { Goiaba podre com larvas } \\
\text { deC. capitata }\end{array}$ & $42,0 \pm 4,43 a$ & 10,5 & 0,0 & 0,0 \\
\hline $\begin{array}{c}\text { Goiaba podre com larvas } \\
\text { de A . fraterculus }\end{array}$ & $30,0 \pm 4,73 a b$ & 7,5 & 0,0 & 0,0 \\
\hline Controle & $0,0 c$ & 0,0 & 0,0 & 0,0 \\
\hline
\end{tabular}




\subsection{Considerações finais}

A orientação de insetos parasitóides por meio de semioquímicos emitidos pelas plantas ou de partes destas tem sido mencionada por diversos autores como uma das formas mais usuais na local ização do hábitat de seu hospedeiro e da garantia de sua sobrevivência (Vinson, 1976; Greany et al., 1977; Jones, 1986; Tumlinson et al., 1993; Henneman et al., 2002; Guimarães \& Zucchi, 2004). No caso de parasitóides de moscas-das-frutas, há consenso que os voláteis de frutos representam importante fonte de orientação para o hospedeiro, principalmente os voláteis de frutos podres para D . Iongicaudata (Greany et al., 1977; Leyva et al., 1991; Messing \& Jang, 1992; Purcell et al., 1994) e em maturação inicial (de vez) para D. areolatus (Matrangolo et al., 1988; Aguiar-Menezes, 2000), além da presença de larvas moscas-das-frutas em diferentes estádios nestes frutos.

D. Iongicaudata é na atualidade a espécie exótica mais extensamente empregada em programas de controle biológico de moscas-das-frutas devido à facilidade de criação massal e fácil adaptação às várias espécies de moscas-dasfrutas de importância econômica, tais como A fraterculus, A. suspensa, A. Iudens (Loew), A .obliqua (Macquart), A. striata Schiner, A. serpentina (Wiedemann) e C. capitata (Sivinski, 1996; Ovruski et al., 2000). Contudo, as evidências recentes quanto à alta capacidade de orientação e parasitismo dos parasitóides nativos como D. areaolatus demonstram a necessidade de se incrementar os estudos com esse parasitóide, visando tornar o controle biológico de moscas-das-frutas mais eficientes. 


\section{CONCLUSÕES}

1) As fêmeas deD iachasmimor pha longicaudata respondem aos voláteis de goiabas podres (em fermentação), independentemente da presença de larvas de moscas-das-frutas;

2) As fêmeas de D oryctobracon areolatus respondem aos voláteis de goiabas tanto em maturação inicial (devez) quanto podres, independentemente da presença de larvas de moscas-das-frutas;

3) As fêmeas de D. Iongicau data e D . areolatus são mais atraídas por goiabas com larvas do que aquelas sem larvas de moscas-das-frutas;

4) As fêmeas de $D$. Iongicaudata não diferenciam por meio dos voláteis de

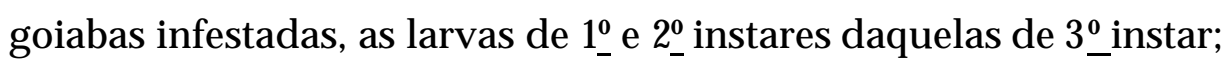

5) As fêmeas de D. Iongicaudata orientam-se com maior freqüência aos voláteis de goiabas com larvas de Ceratitis capitata do que aos voláteis de goiabas com larvas deA nastrepha fraterculus.;

6) As fêmeas de $D$. areolatus orientam-se com maior freqüência aos voláteis de goiabas com larvas de A fraterculus do que aos voláteis de goiabas com larvas de C. capitata; 
7) As fêmeas de A sobara anastrephae orientam-se indiferentemente aos voláteis tanto para goiabas com larvas de C. capitata quanto aos voláteis de goiabas com larvas deA . fraterculus;

8) Em telado, as fêmeas de D. Iongicaudata foram atraídas para goiabas com larvas de moscas-das-frutas colocadas em armadilhas no solo,

9) Em telado, as fêmeas de D. areolatus não foram atraídas para goiabas com larvas de moscas-das-frutas colocadas em armadilhas no solo. 


\section{REFERÊNCIAS BIBLIOGRÁFICAS}

AGUIAR-MENEZES, E.L. Aspectos ecológicos de populações de parasitóides Braconidae (Hymenoptera) de Anastrepha spp. Schiner, 1868 (Diptera: Tephritidae) no município de Seropédica. Seropédica, 2000. 133 p. Tese (Doutorado) - Universidade Federal Rural do Rio de Janeiro.

AGUIAR-MENEZES, E.L.; MENEZES, E.B. Parasitismo sazonal e flutuação populacional de Opiinae(Hymenoptera: Braconidae), parasitóides de espécies de Anastrepha (Diptera: Tephritidae), em Seropédica, RJ. Neotropical Entomology, v. 31, n. 4, p. 589-595, 2001.

AGUIAR-MENEZES, E.L.; MENEZES, E.B. Effect of time of permanence of host Fruits in the field on natural parasitism of A nastrepha spp. (Diptera: Tephritidae). N eotropical Entomology, v. 31, n. 4, p. 589-595, 2002.

AGUIAR-MENEZES, E.L.; MENEZES, E.B.; SILVA, P.S.; BITTAR, A.C.; CASSINO, P.C.R. Native hymenoperan parasitoids associated with A nastrepha spp. (Diptera; Tephritidae) in Seropedica city, Rio de Janeiro, Brazil. Florida Entomologist, v. 84, n. 4, p. 706-711, 2001. 
ANDRIGUETO, J.R.; KOSOSKI, A.R. Programa de desenvolvimento da fruticultura brasileira e a inserção da produção integrada nos mercados nacional e internacional In: ZAMBOLIM, L. (Ed.). Manejo integrado: produção integrada; fruteiras tropicais; doenças e pragas. Viçosa: Suprema Gráfica e Editora 2003. p. 1-6.

ARAÚJO, E.L. Dípteros frugívoros (Tephritidae e Lonchaeidae) na região de Mossoró/ Assu, Estado do Rio Grande do Norte. Piracicaba, 2002. 112 p. Tese (Doutorado) - Escola Superior de Agricultura "Luiz de Queiroz", Universidade de São Paulo.

ARAÚJO, E.L.; ZUCCHI, R.A. Parasitóides (Hymenoptera: Braconidae) de moscas-das-frutas (Diptera: Tephritidae) na região de Mossoró/ Assu, Estado do Rio Grande do Norte. Arquivos do Instituto Biológico, v. 69, n. 2, p. 6568, 2002.

BARANOWSKI, R.; GLEEN, H.; SIVINSKI, J. Biological control of the caribbean fruit fly (Diptera : Tephritidae). Florida Entomologist, v. 76, p. 245-250, 1993.

BRANCO, E.S.; VENDRAMIN, J.D.; DENARDI, F. Resistência às mosca-dasfrutas em fruteiras. In: MALAVASI, A.; ZUCCHI, R.A. (Ed.). M oscas-dasfrutas de importância econômica no Brasil: conhecimento básico e aplicado. Ribeirão Preto: Holos Editora, 2000. cap. 21, p. 161-167.

BURNS, R.E. Caribbean frui fly parasitóide rearing and release procedure manual, Gainesville: Florida Departament of Agriculture \& Consume Service, 1993. $20 \mathrm{p}$. 
CANAL, N.A.; ZUCCHI, R.A. Parasitóides-Braconidae. In: MALAVASI, A.; ZUCCHI, R.A. (Ed.). Moscas-das-frutas de importância econômica no Brasil: conhecimento básico e aplicado. Ribeirão Preto: Holos Editora, 2000. cap. 15, p. 119-126.

CANAL, N.A.D.; ZUCCHI, R.A.; SILVA, N.M.; SILVEIRA NETO, S. A nálise faunística dos parasitóides (Hymenoptera:Braconidae) de Anastrepha spp. (Diptera: Tephritidae) em Manaus e Iranduba, Estado do Amazonas. Acta A mazônica, v. 25, p. 235-246, 1995.

CANCINO D., J.L. Analisis demográfico de uma cepa de Diachasmimorpha longicaudata Ashmead (Hymenoptera; Braconidae) mantenida em condiciones de cria masiva. México, 2002. 70 p. Tesis (Maestria) Universidad Nacional Autonoma de Mexico.

CARVALHO, R.S. Impacto da introdução do braconídeo exótico Diachasmimorpha longicaudata no Recôncavo Baiano, no Semi-árido e na A mazônia e seu potencial de uso no Brasil. (compact disc). In: CONGRESSO BRASILEIRO DE ENTOMOLOGIA, 19., Manaus, 2002. Manaus: SEB, 2002.

CARVALHO, R.S. Estudos de laboratórios e de campo com parasitóide exótico D iachasmimorpha longicaudata A shmead (Hymenoptera; Braconidae) no Brasil. São Paulo, 2003. 182 p. Tese (Doutorado) - Instituto de Biociências, Universidade de São Paulo. 
CARVALHO, R.S. Monitoramento de parasitóides nativos e de tefritideos antes da liberação de Diachasmimorpha longicaudata (Hymenoptera: Braconidae) no submédio São Francisco. Cruz das Almas: Embrapa, CNPMF, 2004. 6p. (Comunicado Técnico).

CARVALHO, R.S.; NASCIMENTO A.S. Criação e utilização de D iachasmimorpha longicaudata para controle biológico de moscas-das-frutas. In: PARRA, J.R.P.; BOTELHO, P.S.M.; CORRÊA-FERREIRA, B.S.; BENTO, J.M.S. (Ed.). Controle biológico no Brasil: parasitóides e predadores. São Paulo: Manole, 2002. cap. 10, p.165-17.

CARVALHO, R.S.; NASCIMENTO A.S.; MATRANGOLO, W.J.R. Controle biológico. In: MALAVASI, A.; ZUCCHI, R.A (Ed.). Moscas-das-frutas de importância econômica no Brasil: conhecimento básico e aplicado. Ribeirão Preto: Holos Editora, 2000. cap. 14, p. 113-117.

CLAUSEN, C.P. Biological control of fruit flies Journal of Economic Entomology, v.49,n.2, p. 176-178,1956.

DE JONG, R.; KAISER, L. Odor learning by Leptopilina boulardi a specialist parasitoid hymenoptera eucoilidae Journal of Insect Behavior, v.4, p. 743750, 1991.

EDWARDS, P.J.; WRATTEN, S.D. Ecologia das interações entre insetos e plantas. São Paulo: EDUSP, 1981. 71 p.

EDWARDS, P.J.; WRATTEN, S.D Wound-induced defenses in plant and their consequences for patterns of insect grazing. Oecologia, v. 59, p.88-93, 1983. 
EIRAS, A.E.; GERK, A.O. Cairomônios e aprendizagem em parasitóides In: VILELA, E.F.; DELLA LUCIA T.M.C. (Ed.). Feromônios de insetos: biologia, química e emprego no manejo de pragas. Ribeirão Preto: Holos Editora, 2001. cap. 15, p. 127-134.

EITAM, A.; HOLLER, T.; SIVINSKI, J.; ALUJA, M. Use of host fruit chemical cues for laboratory rearing of D oryctobracon areolatus (Hymenoptera: braconidae), a parasitoid of anastrepha spp. (Diptera: Tephritidae). Florida Entomologist, v. 86, n. 2, p. 211-216, 2003.

FARIAS, A.M.I.; HOPPER, K.R. Responses of female Aphelinus asychis (Hymenopetra: Aphelinidae) and Aphidius matricariae (Hymenoptera: A phidiidae) to host and plant-host odors. Environmental Entomology, v.26, n.4, p. 989-994, 1997.

GAULD, I.D.; BOLTON, B. The hymenoptera. Oxford: Oxford University Press, 1988. 332 p.

GINGRICH, R.E. Biological control of tephritids fruit flies by inundative releases of natural enemies In: ALUJA, M.; LIEDO, P. (Ed.). Fruit flies. biology and management. New York: Springer-Verlag, 1993. p. 311-318.

GLAS, P.C.G.; VET, L.E.M. Host-hábitat location and host location by D iachasma alloeum Muesebeck (Hym.; Braconidae), a parasitoid of Rhagoletis pomonella Walsh (Diptera: Tephritidae). N etherlands Journal of Zoology, v. 33, p. 41$54,1983$. 
GREANY, P.D.; VINSON, S.B.; LEWIS, W.J. Insects parasitoids: finding new opportunities for biological control. BioScience, v 34, n. 11, p. 690-696, 1984.

GREANY, P.D.; ASHLEY, T.R.; BARANOWSKI, R.M.; CHAMBERS, D.L. Rearing and life history studies on Biosteres (O pius) longicaudatus (Hymenptera: Braconidae). Entomophaga, v. 21, p. 207-215, 1976.

GREANY, P.D.; TUMLINSON, J.H.; CHAMBERS, D.L.; BOUSH, G.M. Chemically mediated host finding by Biosteres (Opius) longicaudatus, a parasitoid of tephritid fruit fly larvae. Journal of Chemical Ecology, v. 3, p. 189-195, 1977.

GUIMARÃES, J.A. Taxonomia e comportamento de parasitismo de Eucolinae (Hymenoptera: Cynipoidea: Figitidae) parasitóides de larvas frugivoras (Diptera). Piracicaba, 2002. 130 p. Tese (Doutorado) - Escola superior de Agricultura "Luiz de Queiroz", Universidade de São Paulo.

GUIMARÃES, J.A.; ZUCCHI, R.A. Parasitism behavior of three species of Eucoilinae (Hymenoptera:Cynipoidea, Figitidae) fruit fly parasitoids (Diptera) in Brazil. N eotropical Entomology, v. 33, n.2, p, 217-224, 2004.

HARE, J.D. Bioassays with terrestrial invertebrates. In : MILLAR, J.G.; HAYES, K.F. (Ed.). M ethods in chemical ecology. Norwell: Kluwer A cademic, 1998. v. 2: Bioassay methods, cap. 5, p. 212-270.

HEN NEMAN, M.L. Maximization of host encounters by parasitoids foraging in the field:females can use a simple rule. Oecologia, v. 116, p. 467-474, 1998. 
HENNEMAN, M.L.; DYRESON, E.G.; TAKABAYASHI, J.; RAGUSO, R.A. Response to walnut olfactory and visual cues by the parasitic wasp D iachasmimorpha juglandis Journal of Chemical Ecology, v. 28, n. 11, p. 22212224, 2002.

IHERING, H.V. Laranjas bichadas. Revista A grícola, v. 6, p. 179, 1901.

JANG, E.B.; MESSING, R.H.; KLUNGNESS, L.M.; CARVALHO, L.A. Flight tunnel responses of D iachasmimorpha longicaudata (Ashmead) (Hymenoptera: Braconidae) to olfactory and visual stimuli. Journal of Insect Behaviour, v.13, p. 525-538. 2000.

JONES, R. L. Orientation by insects parasitoids. In: PAYNE, T. L.; KENNEDY, C.E. (Ed.). Mechanisms in insect olfaction. Oxford: Clarendon Press, 1986. cap. 16, p.149-156.

LATHROP, F.H.; NEWTON, R.C. The biology of Opius melleus Gahan, a parasite of the blueberry maggot. Journal of Agricultural Research, v. 46, p. 143-160, 1933.

LAWREN CE, P.O. Host vibration a cue to host location by the parasite, Biosteres longicaudatu s. O ecologia, v. 48, p. 249-251. 1981.

LEONEL JR., F.L. Espécies de braconidae (Hymenoptera) Parasitóides de moscas-das-frutas (Diptera-Tephritidae) no Brasil. Piracicaba, 1991. 83 p. Dissertação (Mestrado) - Escola superior de Agricultura "Luiz de Queiroz", Universidade de São Paulo. 
LEONEL JR., F.L.; ZUCCHI, R.A.; CANAL D., N .A. Parasitismo de moscas-dasfrutas (Diptera: Tephritidae) por Braconidae (Hymenoptera) em duas localidades do estado de São Paulo. Anais da Sociedade Entomológica do Brasil, v. 25 p. 199-206, 1996.

LEONEL JR., F.L.; ZUCCHI, R.A.; WHARTON , R.A. Distribution and tephritid hosts (Diptera) of braconid parasitoids (Hymenoptera) in Brazil. International Journal of Pest M anagement, v.41, n. 4, p. 208-213, 1995.

LEWIS, W.J.; MARTIN, J.R. Semiochemicals for use with parasitoids: status and future. Journal of Chemical Ecology, v.16, p. 3067-3090, 1990.

LEWIS, W.J.; TUMLINSON J.H. Host detection by chemically mediated associative learning in a parasitic wasp. N ature, v. 331 p.257-259, 1988.

LEYVA, J.L.; BROWNING, H.W.; GILSTRAP, F.E. Effect of host fruit species, size, and color on parasitization of A nastrepha ludens (Diptera: Tephritidae) by Diachasmimorpha longicaudata (Hymenoptera: Braconidae). Environmental Entomology, v.20, p. 1469-1474, 1991.

LIEDO. P.; CANCINO. J.L. Control biologico de moscas de la fruta. In BADII, M.H.; FLORES, A.E.; WONG, L.J.G. (Ed.). Fundamentos y perpectivas de control biologico. Nuevo Leon: Universidad Autonoma de Nuevo Leon, 2000. cap.20, p. 231-242.

LÓPEZ, M.; ALUJA, M.; SIVINSKI, J. Hymenopterous larval-pupal and pupal parasitoids of A nastrepha flies (Diptera: Tephritidae) in Mexico. Biological Control, v.15, p.119-129, 1999. 
LÓPEZ, M.; SIVINSKI, J.; RENDON, P.; HOLLER, T.; BLOEM, K.; COPELAND, R.; TROSTLE, M.; ALUJA, M. Colonization of Fopius ceratitivorus a newly discovered african egg-pupal parasitoid (hymenoptera: braconidae) of Ceratitis capitata (diptera: tephritidae). Florida Entomologist, v. 86, n.1 p. 53 60, 2003.

MALAVASI, A.; SUGAYAMA, R.L.; ZUCCHI, R.A. Biogeografia. In: MALAVASI, A.; ZUCCHI, R.A. (Ed.). Moscas-das-frutas de importância econômica no Brasil: conhecimento básico e aplicado. Ribeirão Preto: Holos Editora, 2000. cap. 1, p. 93-98.

MATRANGOLO, W.J.R.; NASCIMENTO, A.S.; CARVALHO, R.S.; MELO, E.L.; JESUS, M. Parasitismo de moscas-das-frutas (Diptera: Tephritidae) associados a fruteiras tropicais. A nais da Sociedade Entomológica do Brasil, v. 27, p. 593-603, 1998.

MENDES, P.C.D. Avaliação populacional de Ceratitis capitata (Wied.) e A nastrepha spp. (Schiner) (Diptera: Tephritidae) e seus parasitóides larvais nativos (Hymenoptera: Braconidae e Figitidae) e introduzido, Diachasmimorpha longicaudata Ashmead (Hymenoptera: Braconidae). Piracicaba, 2001. 84 p. Tese (Doutorado) - Centro de Energia Nuclear na Agricultura, Universidade de São Paulo.

MESSING, R.H.; JANG, E.B. Response of the fruit fly parasitoid Diachasmimorpha longicaudata (Hymenoptera: Braconidae) to host-fruit stimuli. Environmental Entomology, v. 21, p.1189-1195, 1992. 
MORGANTE, J.S. M oscas-das-frutas (Tephritidae): características biológicas, detecção e controle. Brasília: MARA, SENIR, 1991. 19 p. (Boletim técnico).

NASCIMENTO, A.S.; CARVALHO, R.S. Manejo integrado de moscas-das-frutas. In: MALAVASI, A.; ZUCCHI, R.A. (Ed.). M oscas-das-frutas de importância econômica no Brasil: conhecimento básico e aplicado. Ribeirão Preto: Holos Editora, 2000. cap. 22, p. 169-173.

OVRUSKI, S.M.; ALUJA, M.; SIVINSKI, J.; WHARTON, R.A. Hymenopteran parasitoids on fruit-infesting Tephritidae (Diptera) in Latin America and the southern United State: diversity, distribution, taxonomic status and their use in fruit fly biological control. Integrated Pest Management Reviews, v.5, p. 81-107, 2000.

PARÉ, P.W.; TUMLINSON, J.H. Plant volatiles as a defense against insect herbivores Plant Physiology, v. 121, p. 325-331, 1999.

PURCELL, M.F.; JACKCON, C.G.; LONG, J.P.; BATCHELOR, M.A. Influence of guiava ripening on parasitism of the oriental fruit fly,Bactrocera dorsalis,by Diachasmimorpha Longicaudata (Hymenoptera: Braconidae) and other parasitoids. Biological Control, v. 4, p. 396-403, 1994.

RONCHI-TELES, B. Ocorrência e flutuação populacional de espécies de moscas das-frutas e parasitóides com ênfase no gênero Anastrepha (Diptera: Tephritidae) na Amazônia Brasileira. Manaus, 2000. 156 p. Tese (Doutorado) - Instituto Nacional de Pesquisas Amazônicas, Universidade da A mazônia. 
SALLES, L.A. Biologia e ciclo de vida de Anastrepha fraterculus (Wied.). In: MALAVASI, A.; ZUCCHI, R.A. (Ed.). Moscas-das-frutas de importância econômica no Brasil: conhecimento básico e aplicado. Ribeirão Preto: Holos Editora, 2000. cap. 8, p. 81-86.

SCHLISERMAN, P.; OVRUSKI, S.M.; DE COLL, O.R. The establishment of Diachasmimorpha Longicaudata (Hymenoptera: Braconidae) in Misiones, N ortheastern Argentina. Florida Entomologist, v.86, n.4, p. 491-492, 2003.

SIQUEIRA, K.M.M.; FARIAS, A.M.I. Resposta de fêmeas de encarsia formosa gahan (hymenoptera: aphelinidae) aos odores do hospedeiro e da planta hospedeira em olfatômetro de quatro vias. Bragantia, v.62, n.3, p. 447-450, 2003.

SUGAYAMA, R.L. A nastrepha fraterculus (Wiedemann) (Diptera: Tephiritidae) na região produtora de maçãs do Rio Grande do Sul: relação com seus inimigos naturais e potencial para o controle biológico. São Paulo, 2000. 117 p. Tese (Doutorado) - Instituto de Biociências, Universidade de São Paulo.

TUMLINSON, J.H.; LEWIS, W.J.; VET, L.E.M. How parasitic wasps find their hosts. Scientific A merican, v.3 n. 268, p. 100-106, 1993.

TURLINGS, T.C.J.; WACKERS, F.L.; VET, L.E.M.; LEWIS, W.J.; TUMLINSON, J. H. Learning of host-finding cues by hymenopterous parasitoids. In: PAPAJ, D.R.; LEWIS, A.C. (Ed.). Insect learning: ecological and evolutionary perspectives. New York: Chapman \& Hall, 1993. p. 51-78. 
UCHÔA-FERNANDES, M.A.; MOLINA, R.M.S.; OLIVEIRA, I.; ZUCCHI, RA.; CANAL D., N.A.; DÍAZ N.B. Larval endoparasitoids (Hymenoptera) of frugivorous flies (Diptera, Tephritoidea) reared from fruits of the cerrado of the state of Mato Grosso do Sul, Brazil. Revista Brasileira de Entomologia, v. 47, n. 2, p. 181-186, 2003.

VET, L.E.M.; DICKE, M. Ecology of infochemical use by natural enemies in a trophic context. Annual Review of Entomology, v. 37,p. $141-172,1992$

VET, L.E.M.; LENTEREN, J.C. van; HEYMANS, M.; MEELIS, E. An airflow olfactometer for measuring olfactory responses of hymenopterous parasitoids and other small insects. Physiological Entomology, v.8, p.97106, 1983.

VINSON, S.B. Host selection by insect parasitoids. Annual Review of Entomology, v. 21, p. 109-133, 1976.

WALDER, J.M.M. Técnica do inseto estéril-controle genético. In: MALAVASI, A.; ZUCCHI, R.A. (Ed.). M oscas-das-frutas de importância econômica no Brasil: conhecimento básico e aplicado. Ribeirão Preto: Holos Editora, 2000. cap. 19, p. 151-158.

WALDER, J.M.M. Produção de moscas-das-frutas e seus inimigos naturais: associação de moscas estéreis e controle biológico. In: PARRA, J.R.P.; BOTELHO, P.S.M.; CORRÊA-FERREIRA, B.S.; BENTO, J.M.S. (Ed.). Controle biológico no Brasil: parasitóides e predadores. São Paulo: Manole, 2002. cap. 11, p. 181-190. 
WALDER, J.M.M.; LOPES, L.A.; COSTA, M.L.Z.; SESSO, J.N.; TONIN, G.; CARVALHO, M.L.; LARA, P.P. Criação e liberação do parasitóide Diachasmimorpha Longicaudata Ashmead (Hymenoptera: Braconidae) para controle de moscas-da-frutas no Estado de São Paulo. Laranja, v. 16, p. 149153, 1995.

WHARTON, R.A. Classification of the braconid subfamily Opiinae (Hymenoptera). The Canadian Entomologist, v. 120, p. 333-360, 1988.

WHARTON, R.A. Classical biological control of fruit-infesting Tephritidae. In: ROBINSON, A.S.; HOOPER, G. (Ed.). Fruit-flies: their biology, natural enemies and control. Amsterdan: Elsevier, 1989. cap. 9, p. 303-313. (World Crop Pests, 3B).

WHARTON, R.A. Bionomic of the braconidae. Annual Review of Entomology, v. 38, p. 121-143, 1993.

WHARTON, R.A. New genera, species and records of new world Alyssinae (Hymenoptera: Braconidae). Proceedings of the Entomological Society of Washington, v. 96 n. 4, p. 630-664, 1994.

WHARTON, R.A. Introduction. In: WHARTON , R.A.; MARSH, P.M.; SHAREY, M.J. (Ed.). Manual of new world genera of the family Braconidae (H ymenoptera). Lawrence: Allen Press, 1997a. p.1-15.

WHARTON, R.A. Subfamily Alysiinae. In: WHARTON, R.A.; MARSH, P.M.; SHAREY, M.J. (Ed.). M anual of new world genera of the family Braconidae (H ymenoptera). Lawrence : Allen Press, 1997b. p. 85-119. 
WHARTON, R.A. Subfamily Opiinae. In: WHARTON, R.A.; MARSH, P.M.; SHAREY, M.J. (Ed.). M anual of new world genera of the family Braconidae (H ymenoptera). Lawrence : Allen Press, 1997c. p. 379-395.

WHARTON, R.A.; GILSTRAP, F.E. Key to and status of Opiinae braconid (Hymenoptera: Braconidae) parasitoids used in biological control of Ceratitis and Dacus S. I. (Diptera: Tephritidae). Annals of the Entomological Society of America, v. 76, n. 4, p. 721-741, 1983.

WHARTON, R.A.; MARSH, P.M. New world Opiinae (Hymenoptera: Braconidae) parasitic on Tephritidae (Diptera). Journal of the Washington A cademy of Sciences, v. 68, p. 147-167, 1978.

ZUCCHI, R.A. Espécies de Anastrepha, sinonímias, plantas hospedeiras e parasitóides. In: MALAVASI, A.; ZUCCHI, R.A. (Ed.). M oscas-das-frutas de importância econômica no Brasil: conhecimento básico e aplicado. Ribeirão Preto: Holos Editora, 2000a. cap.4, p. 41-48.

ZUCCHI, R.A. Mosca-do-mediterrâneo, Ceratitis capitata (Diptera: Tephritidae) In: VILELA, E.F.; ZUCCHI, R.A.; CANTOR, F. (Ed.). Histórico e impacto das pragas introduzidas no Brasil. Ribeirão Preto: Holos Editora, 2000b. cap.1, p. 15-22.

ZUCCHI, R.A. Taxonomia. In: MALAVASI, A.; ZUCCHI, R.A. (Ed.). M oscasdas-frutas de importância econômica no Brasil: conhecimento básico e aplicado. Ribeirão Preto: Holos Editora, 2000c. cap.1, p. 13-24. 